\title{
Violência urbana em contextos de desigualdade socioeconômica
}

\section{Urban violence in contexts of socioeconomic inequality}

\author{
André Luís Gomes ${ }^{1}$, Neide Maria de Almeida Pinto ${ }^{2}$, Ana Louise \\ de Carvalho Fiúza ${ }^{3}$, Geraldo Magela da Cruz Pereira ${ }^{4}$
}

\begin{abstract}
Resumo
Este estudo objetivou caracterizar e compreender os tipos de violência que estão presentes numa cidade média, localizada em Minas Gerais, tomando como variável as condições de desigualdade socioeconômica e espacial a qual estão expostas as vítimas. Para tanto, o referencial teórico pautouse na teoria da desorganização social e da atividade de rotina. Em termos metodológicos, foi feita uma pesquisa bibliográfica e documental, utilizando dados da Polícia Militar, do Bolsa Família e do CENSUS (2014). Os resultados evidenciaram que o tipo de violência sofrida e os respectivos números de ocorrências apareceram relacionados às regiões de planejamento, à faixa etária e ao perfil socioeconômico dos indivíduos. Verificou-se também que os jovens de cor negra/parda, residentes nas regiões de maior vulnerabilidade e segregação socioespacial, foram mais vítimas de agressões físicas e homicídios. Já os jovens de cor branca, residentes nas regiões menos segregadas e de menor vulnerabilidade social, foram mais afetados pelos roubos. Concluiu-se que a desigualdade socioeconômica a qual estão expostos os jovens das regiões é o elemento propiciador da vitimização deles. Depreende-se dessa análise que os tipos de violência vivenciados na cidade não atingem a todos da mesma forma, variando conforme a região, idade, sexo, cor e condições socioeconômicas.
\end{abstract}

Palavras-chave: Violência urbana; Espaço urbano; Desigualdade social.

\begin{abstract}
This study aimed to characterize and understand the types of violence that are present in a medium city, located in Minas Gerais, taking as a variable the conditions of socioeconomic and spatial inequality to which the victims are exposed. Therefore, the theoretical framework was based on the theory of social disorganization and routine activity. In methodological terms, a bibliographical and documentary research was carried out, using data from the Military Police, Bolsa Família and CENSUS (2014). The results showed that the type of violence suffered and the respective numbers of occurrences appeared related to the planning regions, the age group and the socioeconomic profile of the individuals. It was also found that young people of black / brown color, living in regions of greater vulnerability and socio-spatial segregation, were more victims of physical aggressions and homicides.
\end{abstract}

\footnotetext{
${ }^{1}$ Doutorado em Economia Doméstica pela Universidade Federal de Viçosa (UFV), Viçosa, Minas Gerais, Brasil. Assistente em Administração da Universidade Federal de Viçosa, Viçosa, Minas Gerais, Brasil. E-mail: andre.l.gomes@ufv.br

${ }^{2}$ Pós-doutorado em Ciências Sociais pela Universidade do Minho (UMinho), Braga, Portugal. Professora da Universidade Federal de Viçosa, Viçosa, Minas Gerais, Brasil. E-mail: nalmeida@ufv.br

${ }^{3}$ Pós-doutorado em Ciências Sociais pela Universidade do Minho, Braga, Portugal. Professora da Universidade Federal de Viçosa, Viçosa, Minas Gerais, Brasil.E-mail: louisefiuza@ufv.br

${ }^{4}$ Doutorado em Estatística Aplicada e Biometria pela Universidade Federal de Viçosa, Viçosa, Minas Gerais, Brasil. E-mail: geraldomcpereira@gmail.com
} 
White youth, living in less segregated regions and with less social vulnerability, were more affected by robbery. It was concluded that the socioeconomic inequality to which young people in the regions are exposed is the element that propitiates their victimization. It appears from this analysis that the types of violence experienced in the city do not affect everyone in the same way, varying according to the region, age, sex, color and socioeconomic conditions.

Keywords: Urban violence; Urban space; Social inequality.

\section{Introdução}

O homicídio, tipo de violência urbana mais impactante, por eliminar a vítima e não permitir a sua recuperação (BRANDÃO; COSTA, 2015), tem, ao longo dos anos, apresentado índices cada vez mais alarmantes no Brasil. Tal incidência se verifica, sobretudo, no ano de 2017, quando foram registrados os maiores números, $29.186^{5}$ casos, apenas nos espaços públicos ${ }^{6}$ das cidades (BRASIL, 2020a) ${ }^{7}$.

Parte significativa dos indivíduos que são vítimas de homicídios tem entre 15 e 29 anos, faixa etária que os classifica como jovens pelo Estatuto de Juventude (Lei $\mathrm{n}^{\circ} 12.852$, de 5 de agosto de 2013) (BRASIL, 2013). Além disso, são do sexo masculino e de cor negra/parda ${ }^{8}$, em sua maioria, residentes em áreas pobres, localizadas nas periferias e regiões metropolitanas das cidades (SINHORETTO, 2015). Entretanto, o fato de a maioria das vítimas e dos agressores habitarem áreas pobres da cidade não significa que exista associação entre pobreza e criminalidade violenta (MISSE, 1999), de modo que isso "é o somatório de um processo de concentração de desvantagens sociais e econômicas com baixa capacidade institucional e social de controle que vai gerar estes bolsões de violência (e de miséria também) nas grandes cidades" (BEATO FILHO, 2012, p. 58).
Entre as desvantagens sociais, pode-se citar: altas taxas de vulnerabilidade social, segregação socioeconômica e espacial, baixo capital social e eficácia coletiva, elementos que variam de região para região dentro de uma mesma cidade. Esses elementos estão associados à teoria da desorganização social e da atividade de rotina, que compreendem a violência urbana como um fenômeno socioespacial, ou seja, que:

[...] apresenta tanto uma dimensão social quanto uma dimensão espacial - relacionada tanto à espacialização dos atos violentos nas cidades quanto à influência que os espaços e o modo de vida urbanos têm na configuração de certos tipos deles (MAGRINI, 2014, p. 95).

De acordo com a teoria da atividade de rotina, para um crime ocorrer é necessário que haja um infrator, uma vítima em potencial e a ausência de alguém ou alguma coisa que possa impedir sua ocorrência (COHEN; FELSON, 1979). Já a teoria da desorganização social postula que a criminalidade é resultado da redução da influência das regras sociais existentes sobre o comportamento dos indivíduos de determinada comunidade (THOMAS; ZNANIECKI, 1999).

As teorias da atividade de rotina e da desorganização social têm sido utilizadas em conjunto e com êxito para explicar o motivo que leva uma

\footnotetext{
${ }^{5}$ De acordo com os dados do DATASUS (2020), no ano de 2007 houve 21.188 casos de homicídios nos espaços públicos do Brasil, passando para $29.186 \mathrm{em}$ 2017, um aumento de 14,5 mortes para cada 100 mil habitantes.

${ }^{6}$ Nos termos de Gomes (2002), espaços públicos são as ruas, praças, avenidas e outros locais de uso comum, em que as pessoas têm livre acesso de circulação, estando sujeitas apenas às normas que regulam o comportamento nesses espaços.

${ }^{7} \mathrm{O}$ homicídio se define, para o presente propósito, como a morte de uma pessoa causada por uma agressão intencional de outra (s). Para os dados procedentes de certidões de óbito, o conceito operacional de homicídio se identifica com a soma das categorias da Classificação Internacional de Doenças da OMS (CID-10) referidas à "morte por agressão", "morte por intervenção legal", “morte por operação de guerra" e as respectivas mortes por sequelas (CÁMARA DE COMERCIO DE BOGOTÁ, 2015, p. 5).

${ }^{8}$ Segundo os dados do DATASUS (2020), dos 29.186 casos de homicídios ocorridos no espaço público no ano de $2017,17.366$ eram de jovens na faixa etária de 15 a 29 anos. Desse total, 16.622 eram do sexo masculino, sendo $81 \%$ de cor negra/parda.
} 
mesma cidade a exibir padrões diferentes de criminalidade violenta (SMITH; FRAZEE; DAVISON, 2000; ANDRESEN, 2006; LOUDERBACK; SEN ROY, 2018). Tendo por base as duas teorias, o presente estudo pretendeu caracterizar e compreender os tipos de crimes violentos ${ }^{9}$ (roubos, homicídios e agressões físicas) numa cidade média, Viçosa, estado de Minas Gerais ${ }^{10}$, Brasil, considerando as suas 14 Regiões Urbanas de Planejamento (RUP). Para tanto, foram tomadas como variáveis as condições de desigualdade socioeconômica e espacial as quais estão expostas as vítimas nessas referidas RUP de Viçosa.

Este trabalho está dividido em quatro partes. Além desta introdução, a primeira parte é formada por dois subcapítulos.

No primeiro subcapítulo, abordando a teoria da desorganização social e da atividade de rotina, são apresentados os elementos que estão associados às elevadas taxas de criminalidade nas diferentes regiões de uma mesma cidade. $\mathrm{O}$ segundo subcapítulo trata da relação entre desigualdade socioeconômica e espacial, a qual estão expostas a população urbana das cidades brasileiras e como essas desigualdades convergem para episódios de violência de diferentes tipos e em diferentes locais. A segunda parte trata dos procedimentos metodológicos para alcançar o objetivo proposto e, por fim, a terceira, os resultados da pesquisa e as considerações finais.

\section{Teoria da desorganização social e da atividade de rotina}

Estudos focados na influência da desorganização social sobre a criminalidade e a violência tiveram início com a fundação da Escola de
Chicago ${ }^{11}$, sendo um estudo importante desenvolvido nesse período o de Shaw e McKay (1969). Utilizando as variáveis: baixo status econômico, heterogeneidade étnica e mobilidade residencial, analisaram como a desorganização social afetava as taxas de criminalidade em Chicago ${ }^{12}$.

No estudo que desenvolveram, Shaw e McKay (1969) perceberam que havia uma relação direta entre as condições da comunidade (status econômico, heterogeneidade étnica e mobilidade residencial) e valores sociais, normas e atitudes que repercutiam nas taxas de criminalidade. Eles conseguiram detectar essa informação, já que taxas mais elevadas de criminalidade eram identificadas nas áreas onde os valores e as normas eram deficientes e onde a comunidade convivia com grandes desvantagens econômicas, sociais e culturais, bem como com o maior contato das crianças com criminosos. Essa situação possibilitava às crianças o conhecimento das técnicas de roubo, a criação de vínculos e a aquisição de atitudes necessárias para se tornar um membro do grupo e, com isso, obter ganhos econômicos, prestígio e companheirismo de criminosos cuja estima e aprovação eram vitais para elas.

Dentro desse contexto, as crianças e os jovens estavam expostos a sistemas de valores concorrentes, ou seja, valores e normas sociais das comunidades que organizavam a vida social e outros valores que eram opostos aos valores da comunidade e que possibilitavam a entrada para a criminalidade. Tal situação, por sua vez, não era percebida nas comunidades residenciais de status econômico mais elevado, onde havia uma provisão adequada para as crianças, que lhes garantia acesso aos bens materiais e simbólicos necessários para a educação e para o sucesso. Além disso, como

\footnotetext{
${ }^{9}$ Crimes que ameaçam a integridade física ou a vida da vítima.

${ }^{10}$ Do ano de 2013 para o ano de 2017, a taxa de mortes por 100 mil habitantes em Viçosa passou de 33,23 casos para 54,13. (FUNDAÇÃO JOÃO PINHEIRO, 2019). Valor maior que a média registrada no estado de Minas Gerais que, no mesmo período, passou de 22,9 para 20,4 homicídios por 100 mil habitantes (CERQUEIRA, 2019).

11 Segundo Coulon (1995), o termo "Escola de Chicago" designa o conjunto de trabalhos de pesquisa realizado por professores e estudantes de sociologia da Universidade de Chicago, entre os anos de 1915 e 1940.

${ }^{12}$ Chicago é uma cidade localizada no meio-oeste norte-americano e caracterizada por um rápido processo de urbanização, em que, de 4.470 habitantes, no ano de 1840, chegou a mais de um milhão em 1890. Ou seja, em 50 anos, a cidade apresentou um crescimento de mais de 200 vezes, chegando a 3,5 milhões em 1930 (COULON, 1995).
} 
nessas comunidades as normas sociais e os valores eram mais uniformes e consistentemente convencionais, não havia possibilidade de escolha entre um valor e outro, resultando em um baixo número de casos de criminalidade $^{13}$ (SHAW; McKAY, 1969).

$\mathrm{Na}$ atualidade, a teoria da desorganização social tem sido utilizada para explicar os motivos que levam determinados espaços da cidade a terem taxas de criminalidade mais elevadas do que outras. Para tanto, a teoria tem, nos mecanismos de vizinhança, os elementos principais para o controle dos delitos, sobretudo, os laços sociais dos moradores e o grau em que exercem o controle social ${ }^{14}$, formal e informal (KUBRIN; WEITZER, 2003), sendo o controle social formal o exercido pela polícia e o judiciário e as prisões, e o controle social informal realizado pela família, escola e grupos sociais, associações e movimentos sociais (SANTOS, 2004).

No controle social informal, os residentes em determinada área da cidade atuam permitindo ou inibindo condutas consideradas desordenadas ou criminais, a partir de ações como: vigilância das ruas, intervenção direta em problemas, questionamento de pessoas sobre atividades suspeitas, advertência de indivíduos que estão se comportando mal, e informando aos pais sobre a má conduta de seus filhos (KUBRIN; WEITZER, 2003). Entretanto, para que o controle social informal funcione, é necessário maior capital social e eficácia coletiva.

O capital social são as conexões entre indivíduos, como as redes sociais ${ }^{15}$ e as normas de reciprocidade e confiabilidade (PUTINAM, 2000), que são dependentes do nível de densidade dos laços entre os vizinhos, a frequência de interação e padrões de vizinhança (SAMPSON; MORENOFF; GANNON-ROWLEY, 2002). Segundo os autores citados, esses elementos estão intrinsecamente ligados à eficácia coletiva, ou seja, a disposição dos moradores de uma determinada localidade em exercer o controle social informal, a partir de intervenções nas ações dos indivíduos dentro da sua vizinhança, as quais dependem da confiança mútua e das expectativas compartilhadas no que tange ao bem comum e público. Dentro desse contexto, para Zaluar e Ribeiro (2009, p. 184), "comunidades com maior capital social, ou seja, onde existisse mais confiança, mais reciprocidade, mais sociabilidade, mais solidariedade e mais associações vicinais, teriam taxas de criminalidade mais baixas e escolas mais eficientes".

Após a publicação do estudo de Shaw e McKay (1969), outras pesquisas focadas na teoria da desorganização social surgiram e, com elas, outras variáveis relacionadas à desigualdade socioeconômica e sociodemográfica, como as pesquisas de Stark (1987) e de Sampson e Groves (1989). Stark (1987), objetivando ampliar a compreensão das fontes ecológicas de comportamento desviante, abandonou a explicação das abordagens psicológicas sociais de que o desvio teria como causa as características individuais e focou o estudo nas abordagens da sociologia do desvio, que entendem a criminalidade como causa das características dos lugares e dos grupos. Para tanto, trabalhou com um conjunto integrado de hipóteses e utilizou as variáveis: densidade; pobreza; uso misto; transitoriedade; e dilapidação, as quais

${ }^{13}$ Os autores ressaltam no texto que apesar da criminalidade ser percebida como uma força poderosa dentro da comunidade, ela não era suficientemente poderosa para fazer com que os indivíduos se tornassem criminosos, visto que o sistema dominante era o de valores tradicionalmente convencionais incorporados na família, igreja, escola e em outras instituições e organizações. Logo, as diferenças individuais, de personalidade, os relacionamentos familiares e o contato com outras instituições ou grupos colaboravam para a entrada ou não do indivíduo no mundo do crime.

${ }^{14}$ O termo controle social pode ser definido como a capacidade de regulação das sociedades em função dos princípios e valores desejados (JANOWITZ, 1975).

15 Além de promover o controle social ao manter a disciplina e o seu cumprimento, entre aqueles sob sua responsabilidade, as redes sociais propiciam também: 1) apoio familiar, identificado mais nas famílias inatas, com poucos filhos e onde um dos pais tem mais tempo para se dedicar à educação dos mesmos, do que nas famílias monoparentais ou aquelas em que os pais trabalham; e 2) benefícios através de redes extrafamiliares, que são os ativos adquiridos quando se está dentro de uma rede de relações, tais como a possibilidade de conseguir um emprego e de mobilidade no que tange à ascensão na carreira profissional e sucesso empresarial (PORTES, 1998). 
eram consideradas aspectos dos bairros urbanos que caracterizavam as áreas de criminalidade e que nunca foram listados pelos membros da Escola de Chicago, mas que permeava toda a literatura sobre o assunto.

Sampson e Groves (1989), utilizando dados de uma pesquisa nacional realizada em 1982, em 238 localidades na Grã-Bretanha, analisaram se o baixo status econômico, heterogeneidade étnica, mobilidade residencial e perturbação familiar levavam à desorganização social da comunidade, aumentando as taxas de criminalidade e delinquência. A partir da análise feita, os autores concluíram que o controle social era menor nas comunidades urbanas do que nas suburbanas e rurais, visto que a urbanização enfraquecia o parentesco local, as redes de amizade e impedia a participação social nos assuntos locais. Além disso, a ruptura familiar interferia no controle dos filhos, tendo efeito positivo direto na prevalência de grupos de adolescentes na esquina e no aumento das taxas de criminalidade.

Outra teoria importante na compreensão espacial da criminalidade é a teoria da atividade de rotina, que, segundo Cohen e Felson (1979), apresenta três elementos como fundamentais para a ocorrência de um crime em que a vítima e o agressor têm contato direto. O primeiro, a existência de um provável criminoso, ou seja, alguém que por algum motivo pudesse cometer um crime. $\mathrm{O}$ segundo, um alvo adequado, podendo este ser uma pessoa ou um objeto, determinado a partir dos seguintes elementos:

[...] valor (ou seja, a conveniência material ou simbólica de um alvo pessoal ou de propriedade para os agressores), visibilidade física, acesso e a inércia de um alvo contra tratamento ilegal por parte dos agressores (incluindo peso, tamanho e recursos anexos ou bloqueados de propriedade que inibem sua remoção ilegal) e a capacidade física de vítimas pessoais de resistir a agressores com ou sem armas (COHEN; FELSON, 1979, p. 591).

E o terceiro, a ausência de um guardião, ou seja, alguém capaz de conter um crime. Apesar de a polícia ser a mais adequada para evitar a ocorrência de um ato criminoso, dificilmente está por perto no momento de um crime. Nesse caso, vizinhos, amigos, entre outros indivíduos, são os mais adequados para inibir casos de criminalidade (COHEN; FELSON, 1979).

Com relação aos elementos que contribuem para que as taxas de criminalidades sejam mais elevadas em um dado espaço da cidade, bem como para que alguns indivíduos sejam mais vítimas, Beato, Peixoto e Andrade (2004, p. 76) destacam cinco elementos: 1) exposição da vítima ao agressor, tempo em que o indivíduo frequenta locais públicos, estabelecendo contatos e interações sociais, sendo, nesse caso, o estilo de vida do indivíduo o elemento determinante na presença e intensidade dos outros elementos, visto que o estilo de vida: "determina em que medida os indivíduos se expõem ao frequentar lugares públicos, qual a sua capacidade de proteção, seus atrativos e a proximidade com os agressores"; 2) proximidade entre a vítima e o agressor se refere aos contatos sociais entre os dois indivíduos, em que o local de residência, características socioeconômicas, atributos de idade e sexo, bem como a proximidade de interesses culturais são fatores que podem favorecer a vitimização; 3) capacidade de proteção da vítima, elemento que está intrinsecamente relacionado ao estilo de vida da vítima, pois quanto maior a capacidade de se proteger de um crime ao evitar contatos com possíveis agressores, menores são as chances de vitimização. Logo, andar de carro e não de ônibus e ter segurança privada pode reduzir o contato com criminosos que podem estar nesses lugares e ao mesmo tempo reduzir as chances de vitimização; 4) menor possibilidade de resistência do indivíduo e maior retorno esperado pelos criminosos: a pouca ou nenhuma capacidade de resistência da vítima é um elemento atrativo para o criminoso, visto que tende a reagir com pouca intensidade, possibilitando menor risco de aprisionamento. Já o maior retorno diz respeito a maior possibilidade de ganhos nas abordagens de alguns indivíduos; assim, indivíduos que oferecem maiores ganhos para o criminoso têm maiores chances de vitimização; e 5) natureza dos delitos, 
como cada elemento anteriormente citado exerce uma influência diferente na determinação do crime, a natureza do delito permite determinar a proporção de cada elemento citado na vitimização.

Uma vez que a questão espacial se coloca como elemento importante na teoria da desorganização social e da atividade de rotina, estudos como os de Simcha-Fagan e Schwartz (1986), Sampson e Wooldredge (1987), Smith, Frazee e Davison (2000), Moriarty e Williams (1996), Andresen (2006), e Louderback e Sen Roy (2017) têm utilizado as duas teorias em conjunto e obtido bons resultados na explicação das elevadas taxas de criminalidade e vitimização em determinados espaços da cidade.

Simcha-Fagan e Schwartz (1986), utilizando dados de uma pesquisa realizada com adolescentes do sexo masculino de 12 bairros da cidade de Nova York, analisaram as características de vizinhança que afetavam as taxas de delinquência e criminalidade. Os fatores importantes considerados nessa análise foram o nível de participação organizacional da comunidade, a extensão da desordem e a subcultura criminal.

Sampson e Wooldredge (1987) verificaram a diferença no risco de vitimização de 10.905 pessoas residentes na Inglaterra e no País de Gales, relacionando os casos de vitimização com as características demográficas, as atividades de rotina no estilo de vida e o contexto de comunidade. Moriarty e Williams (1996) pesquisaram a vitimização por crimes contra a propriedade em 400 famílias residentes em bairros com taxas baixas e altas de criminalidade na parte ocidental da Virgínia.

Smith, Frazee e Davison (2000) verificaram em um estudo sobre assaltos a ruas no sudeste norte-americano, vários efeitos da interação entre as variáveis de desorganização social e da teoria da atividade rotineira. Andresen (2006), para saber como os diferentes atributos demográficos, econômicos e sociais das unidades de fronteira do censo em Vancouver, Colúmbia Britânica, Canadá, interferiam na taxa de crimes, utilizou dados extraídos do Departamento de Polícia de Vancouver, dados sociodemográficos e socioeconômicos do censo do Statistics, em 1996.

Por fim, Louderback e Sen Roy (2017), por meio de dados de 290 setores do censo no Condado de Miami-Dade, Flórida, Estados Unidos, pesquisaram os efeitos dos programas de Vigilância do Crime Comunitário sobre as taxas de roubos e agressões.

Apesar do contexto brasileiro ser diferente do apresentado nos estudos internacionais, as teorias da desorganização social e da atividade de rotina também têm sido utilizadas em estudos sobre o Brasil que, segundo Cerqueira, Lobão e Carvalho (2005), têm na exclusão social, conjugada com a desigualdade socioeconômica, os principais fatores para a criminalidade. Nesse sentido, o próximo tópico aborda elementos das duas teorias citadas e que estão associadas às altas taxas de criminalidade em determinados espaços do Brasil.

\section{Violência urbana, desigualdade socioeconômica e espacial}

O espaço é organizado por meio de padrões de diferenciação social e separação, que variam em função da cultura e da história, evidenciando os princípios estruturadores da vida pública e, ao mesmo tempo, indicam como os diferentes indivíduos se inter-relacionam no espaço urbano. Nesse sentido, as cidades modernas são marcadas por desigualdade social e segregação espacial, havendo diferenciação na apropriação do espaço, por diferentes grupos, em função do poder e da posição social. Dentro desse contexto, a segregação que tende a prevalecer é aquela em que os grupos com maior influência e condição econômica tendem a se concentrar nas áreas mais estruturadas e em locais privilegiados da cidade, em que o preço da terra supera a possibilidade de acesso de grande parte da população (CALDEIRA, 2008).

Nas áreas habitadas pela população de maior renda e influência, geralmente há uma maior concentração de serviços, equipamentos e infraestrutura pública, como escolas, comércio, emprego, 
saneamento, energia elétrica, telefonia, rede viária e de transporte. Por outro lado, a população com menor poder aquisitivo e influência tende a habitar áreas mais distantes, às vezes sem controle no uso do solo e com pouco ou nenhum serviço, equipamento público e infraestrutura urbana e onde o preço da terra é mais baixo, se comparado ao preço nas áreas com localização privilegiada (SCHVASBERG, 2003).

Apresenta-se assim a situação de muitas periferias e favelas das cidades brasileiras espaços densamente povoados e desorganizados socialmente, onde os habitantes, em sua maioria, são pobres, com baixos níveis educacionais, desempregados, às vezes ocupando postos com remuneração mínima ou vivendo na informalidade. A estrutura deficitária dessas comunidades não permite que atuem efetivamente no controle social do crime e da violência, tendo como resultado uma baixa eficácia coletiva. Essa situação facilita o surgimento de organizações criminosas que, pelo uso da força, acabam tendo o controle dessas áreas, transformando-as em ponto de venda de drogas, de disputas de territórios e de circulação de armas de fogo (CAVALCANTI, 2017).

Nesse contexto, os mais afetados são os jovens, principalmente aqueles que possuem famílias com bases estruturais fracas, residentes em localidades com alta incidência de abuso de drogas e álcool. Eles são captados por jovens do tráfico, com os quais possuem alguma relação, ampliando a circulação de armas de fogo, as quais passam a constituir não apenas meio de defesa, mas de status dentro de determinada área (CAVALCANTI, 2017).

Entretanto, a pobreza e a carência material e simbólica, que caracterizam muitos bairros, não podem ser entendidas como causa explicativa da violência. É preciso entender que existe uma combinação de variáveis ligadas aos problemas de socialização primária deficiente na família e de uma socialização baseada em carências materiais, educativas, de inserção no mercado de trabalho e de dispositivos socialmente integradores de diversas características, como, por exemplo, ligados ao lazer, ao esporte e a atividades lúdicas (GADEA et al., 2018).

Dessa forma, os fatores capazes de gerar autores e vítimas de violência não estão relacionados apenas na manifestação da violência em determinado espaço da cidade. A sua produção também se dá a partir de uma divisão social do espaço e de um urbanismo particular, que irá produzir tipos de violência de acordo com o nível de segregação de uma dada área (CARRIÓN, 2008). Assim, ao mesmo tempo em que nas áreas nobres ocorrem os roubos, nas áreas de menor poder aquisitivo são os homicídios que prevalecem (CANO, 1998). Nesse sentido, a violência urbana não é a mesma em todas as regiões, existindo tipos de violência que se manifestam mais em alguns espaços do que em outros, em função da vulnerabilidade social e do nível de segregação a qual determinada população está exposta.

Apesar dos estudos brasileiros estarem de forma majoritária associados aos contextos das cidades de grande porte, buscando aprofundar a temática e a contribuição ao tema, o presente estudo busca analisar a relação entre certos aspectos da desigualdade social e as taxas de criminalidade e vitimização no contexto de uma cidade média, do interior de Minas Gerais. Ou seja, existe uma recorrência dos tipos de violência urbana associados às grandes metrópoles àquela presente no contexto estudado? Os tipos de violência diagnosticados também estão associados à vulnerabilidade social e ao nível de segregação socioespacial a qual essas populações estão expostas? Esses serão os pontos centrais de investimento nos próximos tópicos.

\section{Procedimentos metodológicos}

Para alcançar o objetivo proposto neste estudo, foram utilizados dados secundários obtidos por meio de pesquisa bibliográfica e documental. A pesquisa bibliográfica relacionou-se às categorias, espacialização da violência, vulnerabilidade social e segregação social, tomando como referência as 
publicações acadêmicas e informações do Instituto Brasileiro de Geografia e Estatística (IBGE), do Ministério do Desenvolvimento Social (MDS) e do Centro de Promoção do Desenvolvimento Sustentável (CENSUS ${ }^{16}$ ).

Já a pesquisa documental baseou-se nos dados da $97^{\text {a }}$ Companhia Especial de Polícia Militar sediada em Viçosa, do setor da Prefeitura Municipal de Viçosa que trabalha com o Programa Bolsa Família e do Centro de Referência Especializado de Assistência Social (CREAS). Na Polícia Militar pesquisou-se, a partir dos boletins de ocorrência, nos anos de 2013 a 2018, dados sobre os homicídios, as agressões físicas e os roubos consumados nas diferentes regiões de Viçosa, bem como o perfil das vítimas, em termos de idade, sexo e cor.

Já no setor da Prefeitura de Viçosa, responsável pelo Bolsa Família ${ }^{17}$, foram pesquisados os números de pessoas cadastradas por bairros. Por fim, no CREAS $^{18}$ foram pesquisados os casos registrados de violência doméstica, abandono ou negligência, alcoolismo, uso de drogas, abuso e exploração sexual de crianças e adolescentes, que são indicadores de desestruturação familiar, bem como os locais em que ocorreram esses casos. Os dados do CREAS e do Bolsa Família, em conjunto, são alguns dos indicadores de vulnerabilidade social e podem ajudar a compreender a espacialização da violência urbana.

As análises desenvolvidas no presente estudo se basearam nos dados que foram reunidos por Regiões Urbanas de Planejamento (RUP) que, de acordo com o CENSUS, é o agrupamento de bairros e ruas que apresentam características semelhantes (CRUZ, 2014). Embora os bairros sejam mais homogêneos em termos de características socioeconômicas e problemas enfrentados, as informações mais completas e atualizadas sobre Viçosa são as fornecidas pelo CENSUS (2014), razão que nos levou a fazer a pesquisa por RUP e não por bairros. Após a coleta dos dados, utilizou-se o programa Excel ${ }^{\circledR}$ para que fosse possível identificar indicadores quantitativos e/ou qualitativos capazes de gerar inferências sobre as condições de

${ }^{16}$ O Centro de Promoção do Desenvolvimento Sustentável (CENSUS) é uma Organização Não Governamental com foco em estudos, formação e assessoria nas áreas social, urbanística, ambiental e de gestão pública. Ele apresenta uma análise da cidade de Viçosa, por meio de uma divisão dela em regiões, a qual chama de Regiões Urbanas de Planejamento (RUP). Essas regiões foram formadas a partir do agrupamento de ruas e bairros da cidade, tendo como critério a proximidade e similaridade socioeconômica entre elas. São RUP de Viçosa: 1 - Centro: integrada pelos bairros: Ramos, Clélia Bernardes, Belvedere e Centro. Este último limitado pelas ruas: Gomes Barbosa, Ladeira dos Operários, José Antônio Rodrigues, Dos Estudantes, Av. P. H. Rolfs (da linha férrea até a esquina com a Av. Castelo Branco), Av. Marechal Castelo Branco (até o trevo do Belvedere), Geninho Lentine, Dr. Milton Bandeira, Dona Gertrudes, Tenente Kümmel, Av. Bueno Brandão e Floriano Peixoto. 2 - Acamari: integrada pelos bairros: Romão dos Reis, Rua Nova, Acamari, Vila Alves, Jardim do Vale, Quinta dos Guimarães, Monte Verde e Otávio Pacheco. 3 - Bom Jesus: integrada pelos bairros: Bom Jesus, Bela Vista, Sagrada Família, Estrelas e Conceição. 4 - Nova Viçosa: integrada pelos bairros: Nova Viçosa e Posses. 5 - Fátima: integrada pelo Bairro de Fátima. 6 - Lourdes: integrada pelos bairros: Betânia, Santa Clara (parte baixa, limitada pela Av. JK até a Rua Joaquim Andrade), Lourdes e Al. Fábio Ribeiro Gomes. 7 - Santa Clara: integrada pelos bairros: JK, Santa Clara (parte alta), Maria Eugênia, Coelhas e São Sebastião. 8 - Passos: integrada pelos bairros: Fuad Chequer, Sagrado Coração (Rebenta Rabicho) e pela área limitada pela Rua dos Passos (do Hospital S. J. Batista até a esquina com a Dona Gertrudes), Rua Dr. Brito, Santana, Álvaro Gouveia e Dr. José N. Vaz de Melo. 9 - Santo Antônio: integrada pelos bairros: Julia Molar, Santo Antônio (do Belvedere até o trevo de Coimbra). 10 - Nova Era: integrada pelos bairros: Nova Era, Vale do Sol e União (Morro do Café). 11 - Amoras: integrada pelos bairros: Barrinha, Cidade Nova, Arduíno Bolívar (Amoras), Laranjal (São José), Boa Vista, Vau-Açu, Inácio Martins e Floresta. 12 - Silvestre: integrada pelos bairros: Liberdade, João Braz, Violeira, Recanto da Serra, Parque do Ipê, Inconfidentes, Silvestre e Novo Silvestre. 13 - Fundão: integrada pelo distrito de São José do Triunfo. 14 - Cachoeirinha: integrada pelo distrito de Cachoeira de Santa Cruz. (BRASIL, 2020b).

${ }^{17}$ O Bolsa Família é, segundo o MDS (2018), um programa de transferência direta de renda que atende famílias em situação de extrema pobreza (renda mensal por pessoa de até $\mathrm{R} \$ 89,00$ ) e pobreza (renda mensal por pessoa de $\mathrm{R} \$ 89,01$ a $\mathrm{R} \$ 178,00$ ), desde que possuam crianças ou adolescentes de 0 a 17 anos em sua composição.

${ }^{18}$ De acordo com a Lei no $12.435 / 2011$, o CREAS é a unidade pública de abrangência e gestão municipal, estadual ou regional, cujo objetivo é a prestação de serviços a indivíduos e famílias em situação de risco pessoal ou social. O CREAS juntamente com o CRAS (Centro de Referência de Assistência Social) são as principais formas de proteção social básica e especial a famílias e indivíduos em situação de vulnerabilidade social. Estando localizadas em áreas de maior vulnerabilidade e risco social. Além disso, possuem interface com outras políticas públicas atuando na articulação, coordenação, oferta de serviços, programas, projetos e benefícios assistenciais. 
produção/reprodução de mensagens (BARDIN, 2011). Posteriormente, os dados foram submetidos à análise de conteúdo, em que, seguindo as orientações de Godoy (1995), fez-se a pré-análise, exploração do material e tratamento dos resultados.

Esse conjunto de informações resultaram na produção de tabelas, gráficos e mapas, sendo os grupos apresentados nos mapas criados a partir do desvio-padrão dos dados tabulados no Excel ${ }^{\circledR}$. Por fim, fez-se uma análise de agrupamentos, a qual foi constituída por um conjunto de procedimentos estatísticos que possibilitaram a reunião de elementos com características similares (FARRELLY et al., 2017).

Neste trabalho foi utilizado o agrupamento hierárquico, que permitiu o agrupamento de RUP similares, de acordo com as variáveis: agressão física, roubo, homicídio, renda per capita, Bolsa Família, assistência CREAS, vulnerabilidade e índice de segregação, baseando-se na distância euclidiana como medida de proximidade entre as regiões. Para a visualização dos agrupamentos, foi gerado pelo pacote pheatmap (KOLDE, 2015), do software R (R Development 2018), um heatmap com os dendogramas obtidos para as regiões e para as variáveis consideradas.

\section{Resultados e Discussão}

Para possibilitar uma maior compreensão da desigualdade socioeconômica e da violência urbana na forma de roubos, homicídios e agressões físicas nas 14 Regiões Urbanas de Planejamento (RUP) de Viçosa, este capítulo foi dividido em dois subtópicos. O primeiro trata da desigualdade socioeconômica entre as RUP, a partir da caracterização da cidade de Viçosa e da sua população. O segundo subtópico aborda os roubos, homicídios e agressões físicas nas RUP, relacionando-os com as condições de desigualdade socioeconômica a qual estão expostas as vítimas.

\section{Caracterização da cidade de Viçosa}

O município de Viçosa (Figura 1) está localizado na Zona da Mata de Minas Gerais, possui área territorial de $299,314 \mathrm{~km}^{2}$ e em seus limites situam-se os municípios de Teixeiras, Guaraciaba, Paula Cândido, Coimbra, Cajuri, São Miguel do Anta e Porto Firme. Em 2019, a população de Viçosa foi estimada em 78.846 habitantes (IBGE, 2020), residindo a maior parte $(93,20 \%)$ na área urbana da cidade (CENSUS, 2014).

Figura 1 - Localização da cidade de Viçosa, Minas Gerais.

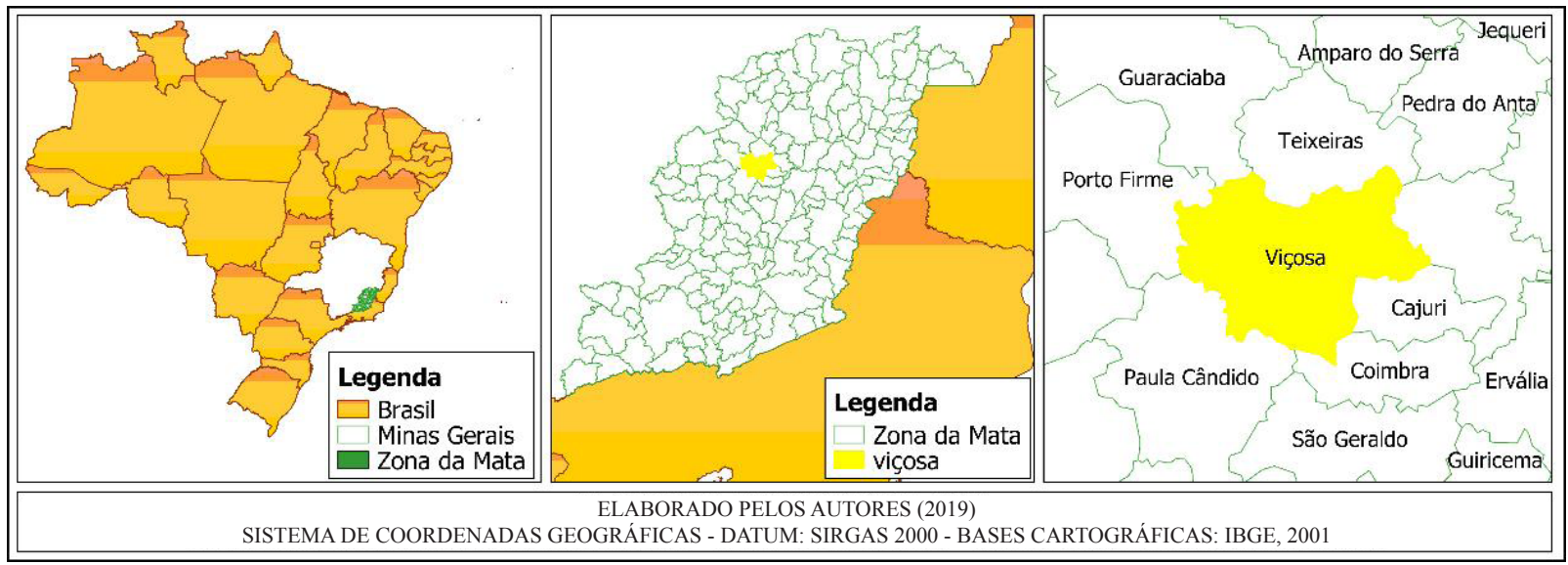

Fonte: os autores, com base nos dados do IBGE (2001).

A cidade é constituída por quatro distritos e 55 bairros, sendo os distritos: a sede, Silvestre, Cachoeira de Santa Cruz e São José do Triunfo.
Além dessa organização territorial, de acordo com o CENSUS (2014), a área urbana pode ser dividida em RUP, critério que será adotado neste estudo e 
que, conforme mostra a Figura 2, são: Acamari, Santa Clara, Passos, Santo Antônio, Nova Era, Bom Jesus, Centro, Nova Viçosa, Fátima, Lourdes, Amoras, Silvestre, Fundão e Cachoeirinha.

Figura 2 - Regiões Urbanas de Planejamento de Viçosa, Minas Gerais.

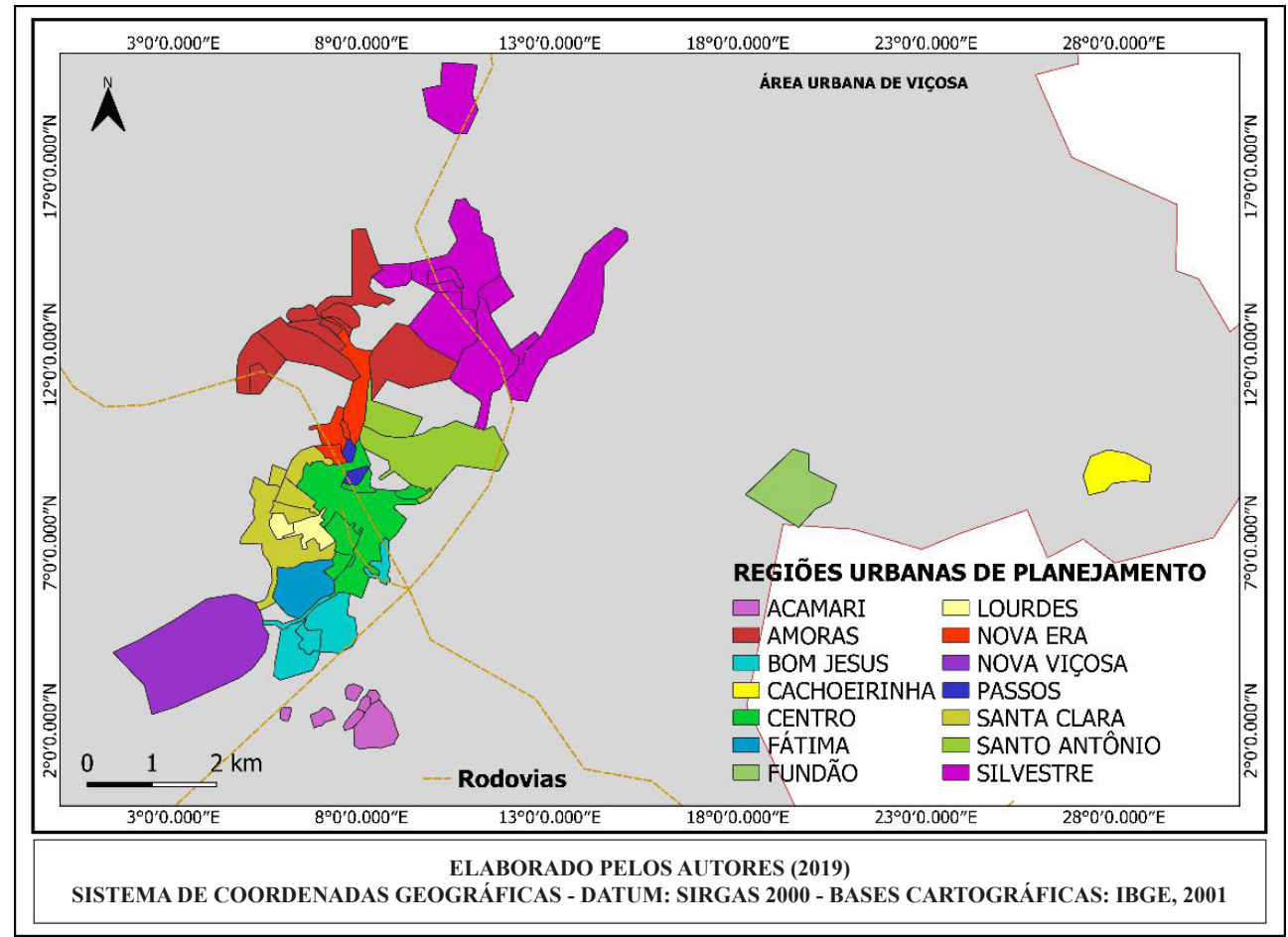

Fonte: os autores, com base nos dados do CENSUS (2014).

A principal atividade desenvolvida em Viçosa é a de serviços, com destaque para a educacional, presente nas instituições de ensino públicas e particulares, de níveis fundamental, médio, técnico e superior, com forte impacto sobre o comércio, construção civil e o ramo imobiliário da cidade (SILVA, 2016). A fundação da Escola Superior de Agricultura e Veterinária (Esav), no ano de 1922, teve papel de destaque na "vocação do município". A referida instituição foi transformada no ano de 1948 em Universidade Rural do Estado de Minas Gerais (UREMG) e, mais tarde, no ano de 1969, federalizada como Universidade Federal de Viçosa (UFV).

Apesar de a cidade possuir uma população inferior a 100 mil habitantes, o que, segundo os critérios do IBGE (2010), a classificaria como cidade de pequeno porte, com base nos estudos de Batella (2017) e Spositto (2001), Viçosa é considerada cidade média. Isso se deve ao seu papel regional e potencial de comunicação e articulação dado pela sua posição geográfica, bem como pelo papel central do consumo na estruturação dos fluxos definidores do papel intermediário dessas cidades.

Assim, o que caracteriza Viçosa como cidade média é a presença da Universidade Federal de Viçosa, no centro da cidade, a União de Ensino Superior de Viçosa (UNIVIÇOSA) e a Escola de Estudos Superiores de Viçosa (ESUV). Ademais, a cidade é influenciadora no crescimento do comércio para essa região e da intensificação do uso do solo, caracterizando novas formas de produção e consumo (BATELLA, 2017).

Durante o desenvolvimento da cidade, a Universidade Federal de Viçosa atraiu um número cada vez maior de pessoas à procura de emprego ou estudo. Esse processo deu-se de forma mais intensa a partir do ano de 1950, período em que a população da cidade quase dobrou a cada 10 anos (RIBEIRO FILHO, 1997). A chegada das demais 
instituições de ensino - a saber: UNIVIÇOSA (2000), ESUV (2001) e Faculdade de Estudos Superiores de Viçosa (2001) - acirrou ainda mais a disputa pela terra urbana, elevando os preços dos lotes.

O crescimento da cidade se revelou desorganizado e irregular, pois de um lado havia uma cidade legal, dentro dos parâmetros urbanísticos, com infraestrutura e serviços, e de outro, uma cidade ilegal, fora dos padrões urbanísticos, baseada na compra clandestina e com os habitantes sem o título de propriedade. Na década de 1990, com exceção dos bairros Ramos, Clélia Bernardes, Acamari, Parque do Ipê e Recanto da Serra, que estavam dentro dos padrões urbanísticos e tinham melhor infraestrutura, a população indigente, em sua maioria, se concentrava nos demais bairros da cidade, alguns com mais infraestrutura e serviços e outros não, como os bairros Amoras, Betânia, Bela Vista, Lourdes, Novo Silvestre, Romão dos Reis, Santa Clara, São Sebastião, Fátima, Nova Viçosa, Silvestre e João Braz. Entretanto, os bairros Lourdes, Fátima, Santa Clara e João Braz não abrigavam, na época, apenas a população indigente, havia bolsões em que essa população se concentrava. Já a população pobre estava concentrada nos bairros Nova Era, Santo Antônio, Bom Jesus, Centro, Vale do Sol e Sagrada Família (RIBEIRO FILHO, 1997).

Tal diferenciação entre as regiões persiste até os dias atuais, e como será visto à frente, podem ser percebidas também em relação à escolaridade, renda, benefícios sociais, infraestrutura e serviços públicos, entre outros. Embora em relação ao ensino educacional Viçosa seja considerada um polo atrativo para pessoas de diferentes cidades e regiões do País, o nível educacional dos habitantes nas RUP é bem diferenciado.

Como evidenciado na Tabela 1, os menores percentuais de frequência à escola da população de 15 a 17 anos está concentrada nas regiões mais vulneráveis. Nessa faixa estão associados os bairros Nova Era e Nova Viçosa, com os menores percentuais de frequência escolar, ou seja, $65,22 \%$ e $64,86 \%$, respectivamente. Com relação à população com nível superior, com idade entre 18 e 24 anos, as maiores frequências observadas foram nas regiões Centro (68,25\%), Lourdes $(64,71 \%)$, Silvestre (64,38\%), Fátima (60,71\%), Santo Antônio $(59,72 \%)$ e Acamari (52,94\%). Já as menores porcentagens, nas regiões de Amoras (15,31\%) e Nova Viçosa $(22,22 \%)$.

Tabela 1 - População em idade escolar e taxa de frequência nas escolas por faixa etária nas Regiões Urbanas de Planejamento (RUP) - 2013.

Total de indivíduos em idade escolar e taxa de frequência escolar

\begin{tabular}{lccccccccc}
\cline { 2 - 8 } RUP & \multicolumn{2}{c}{ 6 a 14 anos } & \multicolumn{2}{c}{15 a 17 anos } & \multicolumn{2}{c}{18 a 24 anos } & \multicolumn{2}{c}{6 a 24 anos } \\
\cline { 2 - 9 } & População & $\%$ & População & $\%$ & População & $\%$ & População & $\%$ \\
\hline Centro & 425 & 97,92 & 266 & 83,33 & 1115 & $\mathbf{6 8 , 2 5}$ & 1806 & 77,45 \\
Acamari & 204 & 100 & 53 & 83,33 & 150 & $\mathbf{5 2 , 9 4}$ & $\mathbf{4 0 7}$ & $\mathbf{8 0 , 4 3}$ \\
Bom Jesus & 1053 & 100 & 460 & 86,54 & 1169 & 41,67 & 2682 & 72,28 \\
Nova Viçosa & 894 & 95,05 & 328 & $\mathbf{6 4 , 8 6}$ & 717 & $\mathbf{2 2 , 2 2}$ & $\mathbf{1 9 3 9}$ & $\mathbf{6 3 , 0 1}$ \\
Fátima & 363 & 97,56 & 168 & 94,74 & 496 & $\mathbf{6 0 , 7 1}$ & 1027 & 79,31 \\
Lourdes & 230 & 100 & 195 & 86,36 & 301 & $\mathbf{6 4 , 7 1}$ & $\mathbf{7 2 6}$ & $\mathbf{8 1 , 7 1}$
\end{tabular}




\begin{tabular}{lcccccccc} 
Continuação & & & & & & & \\
Santa Clara & 850 & 91,67 & 212 & 79,17 & 690 & 30,77 & $\mathbf{1 7 5 2}$ & $\mathbf{6 6 , 1 6}$ \\
Passos & 248 & 96,43 & 177 & 95 & 434 & 44,9 & 859 & 70,1 \\
Santo Antônio & 841 & 97,89 & 407 & 91,3 & 1275 & $\mathbf{5 9 , 7 2}$ & 2523 & 77,54 \\
Nova Era & 478 & 96,3 & 204 & $\mathbf{6 5 , 2 2}$ & 567 & 34,38 & $\mathbf{1 2 4 9}$ & $\mathbf{6 3 , 1 2}$ \\
Amoras & 1018 & 98,26 & 319 & 77,78 & 868 & $\mathbf{1 5 , 3 1}$ & $\mathbf{2 2 0 5}$ & $\mathbf{6 2 , 6 5}$ \\
Silvestre & 451 & 92,16 & 257 & 89,66 & 646 & $\mathbf{6 4 , 3 8}$ & 1354 & 78,43 \\
Fundão & 416 & 95,74 & 221 & 92 & 390 & 31,82 & 1027 & 70,69 \\
Cachoeirinha & 257 & 100 & 133 & 86,67 & 328 & 45,95 & 718 & 72,84 \\
\hline Média & 97,07 & & 83,99 & & 45,55 & & 72,55 \\
\hline Desvio-padrão & & 2,74 & 9,56 & & 16,94 & & 6,81 \\
\hline
\end{tabular}

Fonte: os autores, com base nos dados do CENSUS (2014).

Percebe-se pelos dados que, de forma geral, a maior porcentagem de pessoas na faixa etária de 6 a 24 anos, que frequenta escola, é oriunda das regiões Lourdes (81,71\%) e Acamari (80,43\%), regiões que apresentaram o menor número de pessoas em idade escolar, 726 e 407, respectivamente. As menores porcentagens relativas à população frequente à escola estiveram associadas às regiões Amoras (62,22\%), Nova Viçosa (63,01\%), Nova Era $(63,12 \%)$ e Santa Clara $(66,16 \%)$, todas elas com mais de mil jovens em idade escolar.

Em termos da média e do desvio-padrão, observa-se, respectivamente, uma diminuição da média e um aumento da variabilidade, à medida que se aumenta a faixa etária da taxa de frequência à escola para os três primeiros intervalos. Da faixa etária de 6 a 14 anos, para a faixa etária entre 15 e 17 anos, houve uma queda de 13,08\%, sendo que uma queda ainda mais acentuada é percebida com a passagem da faixa etária entre 15 e 17, para a de 18 a 24 anos, 38,44 pontos percentuais. Notavelmente, os bairros Nova Viçosa, Santa Clara e Nova Era apresentaram taxas abaixo do valor médio para as três faixas etárias consideradas. Os bairros Centro, Acamari, Fátima, Lourdes e Santo Antônio mostraram taxas próximas ou superiores à taxa média.

A baixa renda per capita, o alto número de pessoas beneficiadas pelo Bolsa Família, cujo benefício é concedido às famílias em situação de pobreza ou extrema pobreza, e o alto número de famílias atendidas pelo CREAS em decorrência de problemas relacionados à violência doméstica, abandono ou negligência, alcoolismo, uso de drogas e abuso ou exploração sexual de criança ou adolescente são indicativos de vulnerabilidade social ${ }^{19}$. Segundo Abramovay et al. (2002), esse fenômeno está também relacionado à violência sofrida e praticada pelo jovem.

Ao se analisar esses dados (renda per capita das famílias, incidência de Bolsa Família e taxa de pessoas atendidas pelo CREAS) e a região urbana a qual essas famílias residem, percebe-se que esses auxílios e benefícios sociais diminuem conforme o aumento da renda per capita e que variam de acordo com a RUP (Figura 3).

${ }_{19}$ Para Abramovay et al. (2002), vulnerabilidade social é o resultado negativo da relação entre a disponibilidade dos recursos materiais ou simbólicos dos atores, sejam eles indivíduos ou grupos, e o acesso à estrutura de oportunidades sociais, econômicas, culturais que provêm do Estado, do mercado e da sociedade. 
Figura 3 - Renda per capita, taxa de beneficiados pelo Programa Bolsa Família e taxa de famílias assistidas pelo CREAS nas RUP - 2019.

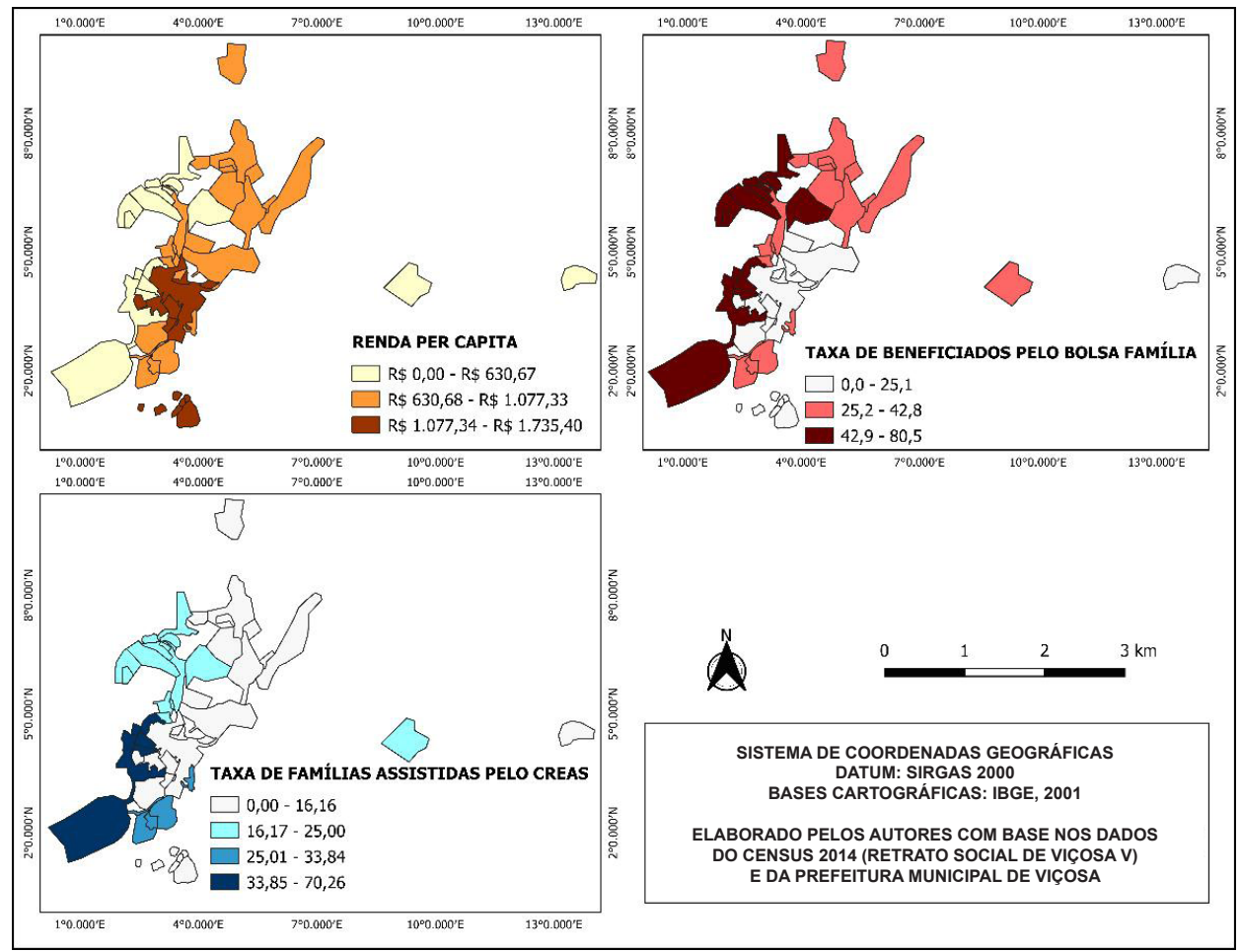

Fonte: os autores, com base nos dados do CENSUS (2014) e do setor do Bolsa Família da Prefeitura Municipal de Viçosa (VIÇOSA, 2020).

Os dados apontam que as maiores rendas per capita estão concentradas nas regiões Acamari (R\$ $1.735,40)$, Lourdes (R\$ $1.356,84)$ e Centro (R\$1.638,01), cujas regiões concentram o maior número de pessoas com ensino superior, indicando a educação como reflexo do nível de renda. Essas regiões apresentaram as menores taxas de beneficiados com o Bolsa Família e de atendimento CREAS, abaixo de $25,1 \%$ e de $16,16 \%$, respectivamente. Já as maiores ocorrências de Bolsa Família, acima de $42,9 \%$, e de atendimentos do CREAS, acima de 33,84\%, foram registradas nas regiões de menor renda per capita: Santa Clara (R\$ 577,76), Amoras (R\$ 541,44) e Nova Viçosa (R\$ 383,32).

Segundo Silva (2016), dentre as RUP, a região Centro, que concentra a população de renda média e alta, é a região mais verticalizada, densamente povoada e dotada de mais infraestrutura e serviços. Tal concentração é resultado da ação de promotores imobiliários que viram nessa região uma possibilidade de altos lucros, uma vez que está próxima da Universidade Federal de Viçosa, local de trabalho e estudo de considerável número de habitantes da cidade. (RIBEIRO FILHO, 1997).

Apesar de não ser o único fator que estaria relacionado ao fenômeno, os bairros periféricos com maior distância centro-periferia tendem a estar associados aos grupos mais vulneráveis socioeconomicamente no território urbano. Esse é o caso, por exemplo, dos bairros Bom Jesus, Nova Viçosa e Estrelas, cuja população tem renda mais baixa que a do centro da cidade e os bairros estão associados a graves problemas de infraestrutura e serviços urbanos (SILVA, 2016).

Além da distância desses bairros do centro, o poder político e recursos econômicos dos seus residentes tendem a explicar as diferenças havidas nos territórios urbanos. É o caso do Monte Verde, Acamari, Jardins do Vale e Otávio Pacheco, condomínios fechados nas regiões periféricas da cidade, os quais servem de moradia para a população de classe média e alta da cidade (MARIA, 2016). 
Já a Região Norte tem uma diversidade de faixas de renda, sendo local de moradia da população de renda alta nos bairros Liberdade 1 e 2, de média renda no caso do João Braz e de baixa renda, Silvestre e Novo Silvestre, com destaque para o bairro Novo Silvestre, com pouca infraestrutura e serviços urbanos (SILVA, 2016).

A partir da referência desses dados, percebese que em Viçosa, da mesma forma como ocorre em outras cidades, a população de renda mais elevada tende a habitar não apenas as áreas da cidade onde se concentram o maior número de equipamentos públicos, infraestrutura e serviços, mas também as regiões mais bem localizadas, em termos de estradas e rodovias, capazes de facilitar o seu deslocamento.

O tempo de deslocamento, segundo Villaça (2012, p. 69), é "a força mais poderosa que atua sobre a produção do espaço urbano como um todo, ou seja, sobre a forma de distribuição da população e seus locais de trabalho, compras, serviço, lazer etc.". Além disso, o tempo de deslocamento tem forte impacto sobre a renda familiar e saúde dos seus membros, uma vez que quanto mais distantes do centro, maiores são os gastos familiares com transporte, maior cansaço físico e menos horas de sono (VILLAÇA, 2012).

Baseando-se nos elementos citados e em outros, Bastos Filho et al. (2019) elaboraram um índice de segregação para cada RUP de Viçosa, utilizando como variáveis as seguintes características das regiões: distância de cada região em relação ao centro, déficit habitacional, acessibilidade, dados socioeconômicos, infraestrutura, educação, saúde, vulnerabilidade familiar e emprego. Na avaliação dos autores, quanto mais próximo de 1 , mais segregada é a região da cidade, caso, por exemplo, das regiões Santa Clara e Nova Viçosa (Figura 4), consideradas as mais segregadas, apresentando índices de 0,615 e 0,688 , respectivamente.

Figura 4 - Índice de segregação das Regiões Urbanas de Planejamento - 2019.

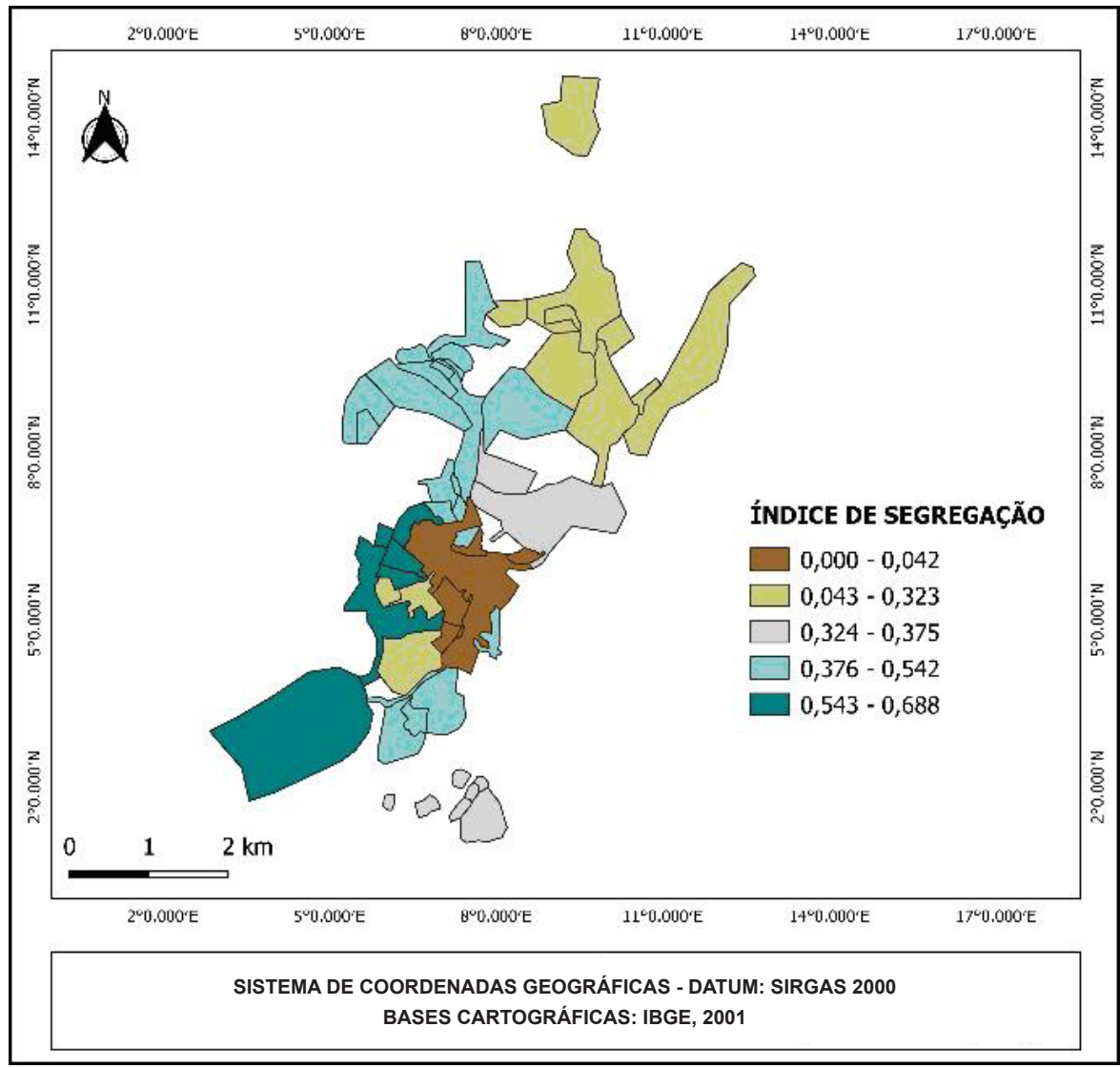

Fonte: os autores, com base nos dados de Bastos Filho et al. (2019). 
Essas regiões, além de estarem mais afastadas da região Centro, apresentam a mais baixa renda média e per capita por família, bem como precários e reduzidos acessos às escolas, PSFs, hospitais e alta vulnerabilidade familiar. Já a região Centro foi classificada como a menos segregada de todas, possuindo um índice de 0,042 , visto que está bem localizada em termos de ruas e rodovias, possui mais infraestrutura, serviços e equipamentos públicos, ausentes ou deficientes nas outras regiões.

Percebe-se pelos dados que Viçosa tem o mesmo quadro desigual e excludente de outras cidades brasileiras no que tange às condições de vida da população. Conforme já apontou Cavalcanti (2017) em sua pesquisa, o crescimento populacional não foi acompanhado por políticas públicas como as de moradia, saúde e educação, capazes de promover uma melhor qualidade de vida.

Dessa forma, vários espaços das cidades são densamente povoados e desorganizados socialmente e a população é pobre, desempregada, com baixos nível de escolaridade e remuneração. Tal situação "diminui as chances de aquisição e aperfeiçoamento de recursos fundamentais para que os jovens aproveitem as oportunidades oferecidas pelo Estado, mercado e sociedade, necessários para poderem ascender socialmente" (ABRAMOVAY et al., 2002, p. 33).

Esse contexto de desigualdade socioeconômica e espacial será analisado a partir de indicadores de violência que são vivenciados pela população de Viçosa nessas diferentes RUP, conforme apresentado nas próximas páginas. Buscarse-á analisar os tipos de violência vivenciados na cidade de Viçosa, correlacionando esses dados com as condições de desigualdade socioeconômica a qual estão expostas as vítimas.

\section{As Regiões Urbanas de Planejamento e a violência urbana em Viçosa}

$\mathrm{O}$ alto índice de violência vivenciado em Viçosa está associado ao seu processo de urbanização que, como aconteceu em boa parte das cidades brasileiras, aprofundou as desigualdades social, econômica e espacial. Esse fenômeno é mais evidente nas periferias da cidade e está ligado, principalmente, ao crime contra a pessoa, como os assassinatos, o roubo, o tráfico e o consumo de entorpecentes, e a própria corrupção de policiais (SILVA et al., 2014).

De acordo com a pesquisa, a desigualdade entre as RUP tem se expressado também em relação à violência urbana que, segundo os dados da $97^{\mathrm{a}}$ Companhia de Polícia Militar, tem sido cada vez mais constante. As análises evidenciam que entre os anos de 2013 e 2018, houve 2.694 casos de crimes violentos ${ }^{20}$ registrados em Viçosa, sendo 1.284 roubos $(47,66 \%), 1.254$ agressões físicas (46,55\%) e 156 homicídios (5,79\%).

Ao se analisar os casos de violência relatados ao longo do período pesquisado (Gráfico 1), percebe-se o crescimento no número de todos eles, principalmente os roubos, que passaram de 0,84 por mil habitantes em 2013 para $4,91 \mathrm{em} 2018$. As agressões físicas saltaram de 2,43 casos para cada mil habitantes registrados em 2013, para 5,81 em 2018. No caso dos homicídios, apesar de se verificar crescimento de 0,21 caso por mil habitantes em 2013 e 0,60 em 2017, percebeu-se uma queda em 2018 , quando foi registrado 0,22 caso.

\footnotetext{
${ }^{20}$ Os dados sobre violência urbana, tais como homicídios, agressões físicas e roubos, fazem parte das estatísticas criminais como, por exemplo, a polícia, a promotoria, o sistema judiciário e penitenciário, bem como dos sistemas de saúde relacionados à mortalidade e à morbidade hospitalar por causas violentas, não podendo ser consideradas um reflexo da magnitude dos casos de violência e criminalidade que ocorrem nos municípios, pois: 1) nem todos os delitos cometidos são notificados à polícia, por falta de confiança nela, da avaliação subjetiva da gravidade do tipo de crime, bem como do custo para se fazer a notificação, em termos de deslocamento e os possíveis embaraços no caso de estar envolvido com o caso; 2) há situações em que o crime ocorre contra a propriedade e esta pode estar ou não coberta por seguro patrimonial; 3) os sub-registros policiais, ou seja, o não registro dos casos de crime e violência por parte dos policiais, devido a práticas corruptas e dos casos de mediação e arbítrio, em que os conflitos são resolvidos informalmente pela polícia, evitando o registro do caso e; 4) dados produzidos com foco na pessoa infratora, objetivando a identificação e a punição dos possíveis culpados, havendo seletividade e estereotipagem na categorização dos suspeitos (LEMGRUBER; MUSUMECI; RAMOS, 2002).
} 
Gráfico 1 - Taxas por mil habitantes de roubos, homicídios e agressões físicas registrados na área urbana de Viçosa - 2013/2018.

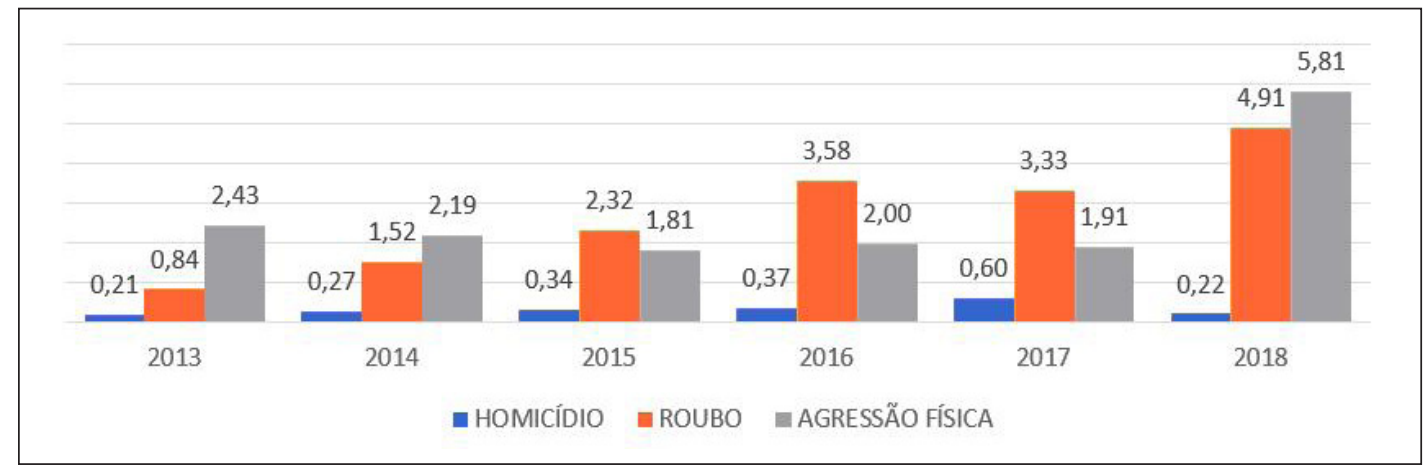

Fonte: os autores, com base nos boletins de ocorrência da $97^{\mathrm{a}}$ Companhia Especial de Polícia Militar de Minas Gerais (2013/2018) e CENSUS (2014).

Os espaços públicos, tais como ruas e praças, foram onde mais se identificaram os casos de violência citados, principalmente das 18 horas da noite às 6 horas da manhã, período em que o número de pessoas transitando por esses locais é baixo. Nesse horário, foram registrados $70 \%$ dos roubos, $61 \%$ dos casos de agressões físicas e $58 \%$ dos homicídios. Esses dados reforçam as afirmações de Ceccato (2016), de que condições específicas são necessárias para a ocorrência de determinados tipos de crimes e violência, como anonimato, isolamento e locais com acesso restrito.

Entre as maiores vítimas de violência em Viçosa, como pode ser verificado no Gráfico 2, estão os jovens, na faixa etária de 20 a 24 anos. Nessa faixa etária, observou-se que as taxas mais elevadas se concentraram nos casos de homicídios $(30,1 \%)$, roubos $(16,9 \%)$ e agressões físicas $(14,2 \%)$.

Gráfico 2 - Porcentagem de homicídios, agressões físicas e roubos por faixa etária - 2013/2018.

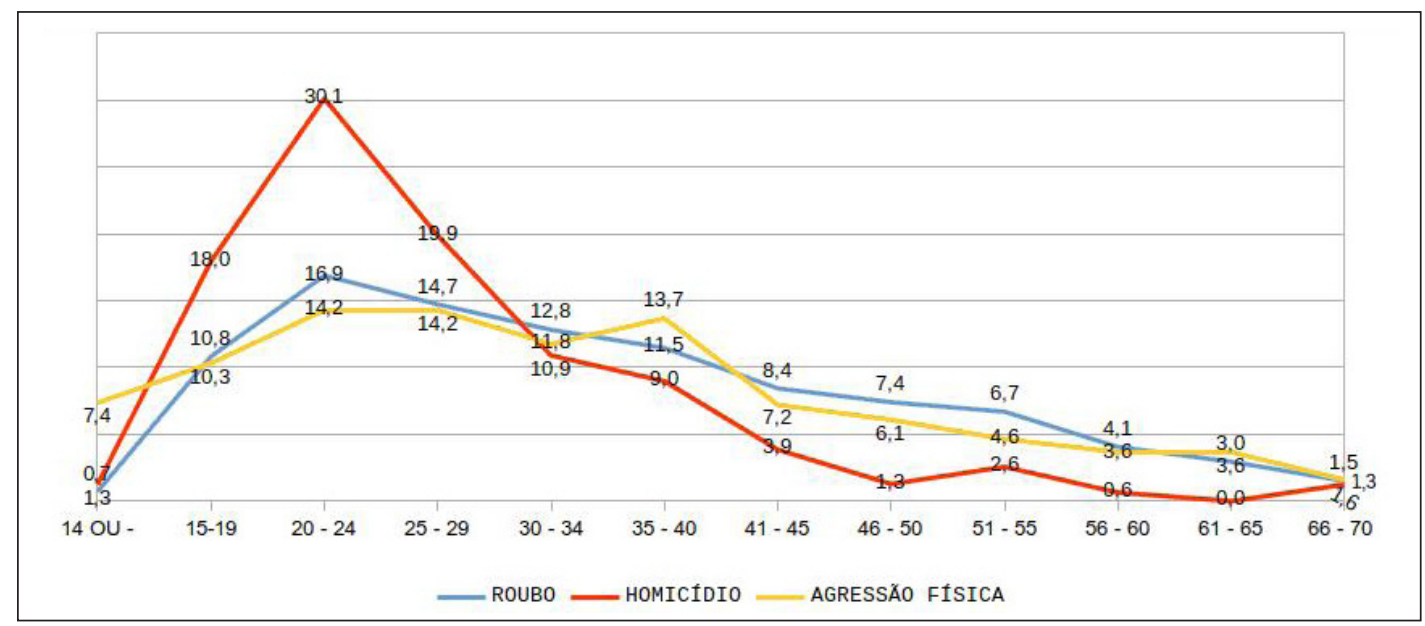

Fonte: os autores, com base nos boletins de ocorrência da $97^{\mathrm{a}}$ Companhia Especial de Polícia Militar de Minas Gerais (2013/2018) (POLÍCIA MILITAR DO ESTADO DE MINAS GERAIS, 2020).

Como mostram os dados, os jovens são as maiores vítimas de homicídios em Viçosa e é uma realidade vivenciada também em outras partes do Brasil. De acordo com Cerqueira et al. (2020), em
2018, 30.873 jovens foram vítimas de homicídios, representando uma taxa de 60,4 homicídios para cada 100 mil jovens e 53,3\% dos homicídios no País. Segundo Barbosa, Kokkonen e Sousa (2021), 
essa violência contra o jovem acontece em diferentes locais, como supermercados, pontos de ônibus e na própria comunidade ou local de moradia, por meio de pancadas, tiros à queima roupa e bala perdida. Além dessas práticas, são também formas de extermínios da população jovem pelo Estado, o abandono material, o descaso, a precariedade de serviços públicos, a exposição ao risco de morte e as abordagens violentas feitas pelos agentes de segurança pública que não levam em consideração a presunção da inocência.

Percebe-se pelos dados que, enquanto os homicídios e as agressões físicas, cujas vítimas estão na faixa etária de 14 anos ou menos, são próximas, apresentando valores de $0,7 \%$ e $1,3 \%$, respectivamente, o mesmo não ocorre em relação aos roubos que, nessa mesma faixa etária, apresentaram percentuais mais elevados: $7,4 \%$ dos casos analisados.

Verifica-se também pelo Gráfico 1 que no intervalo entre 14 e 24 anos a taxa de homicídios apresenta um crescimento mais rápido que o crescimento das taxas de roubo e agressão física. A partir dessa faixa etária, nota-se um decréscimo das três taxas, sendo o decréscimo da taxa de homicídios mais acentuado. Percebe-se que as taxas tendem para valores próximos na faixa etária entre $30 \mathrm{e}$ 34 anos, $12,8 \%, 11,8 \%$ e $10,9 \%$, respectivamente para as taxas de roubo, agressão física e homicídio. Com o aumento das faixas etárias, no intervalo entre 35 e 70 anos, nota-se o decrescimento das três taxas, de modo que a curva da taxa de homicídios permanece abaixo das curvas das taxas de roubo e agressão física.

Poucas diferenças foram observadas entre as taxas de roubo e agressão física, sendo essas duas, em média, maiores que a taxa de homicídio respectivamente 4,05 e 3,47 pontos percentuais. $\mathrm{Na}$ faixa etária entre 66 e 70 anos, observam-se valores próximos e de baixa magnitude para as três taxas, $\mathrm{o}$ que indica que essa faixa etária é alvo igualmente das três modalidades de violência, e que há baixo risco de casos. Essa baixa taxa de idosos e de pessoas com 14 anos ou menos, vítimas de violência, pode estar relacionada ao estilo de vida desses grupos, o qual, segundo Borges (2013), é marcado por maior tempo em família, limitadas interações sociais e menor exposição a situações de violência.

Fazendo uma análise do número de vítimas de violência, apenas do sexo masculino e feminino de cor negra/parda e branca, verifica-se que, em relação aos roubos, das 1.184 vítimas identificadas, a maioria (87\%) era do sexo masculino, sendo $61 \%$ de cor branca e $49 \%$ de cor negra ou parda. Com relação às agressões físicas, houve 1.121 vítimas, $75 \%$ do sexo masculino, sendo que, desse total, $58,01 \%$ eram de cor negra/parda e $41,99 \%$ de cor branca. Com relação aos homicídios, as maiores vítimas também foram do sexo masculino; das 111 vítimas, $98 \%$ eram do sexo masculino e desse total $75,23 \%$ eram de cor negra/parda.

O alto índice de homens vítimas de violência em relação ao de mulheres pode estar associado a fatores culturais da sociedade, em que o homem tende a sofrer mais violência física que as mulheres, devido a sua maior exposição ao risco (JIBAT; NIGUSSIE, 2015). Todavia, para Cerqueira et al. (2020), apesar do número de mortes de mulheres no Brasil ter reduzido a 8,4\% entre os anos de 2017 e 2018, essa redução foi boa apenas para as mulheres de cor branca, pois as negras continuaram e ser vítimas, de forma que, enquanto entre os anos de 2008 e 2018 o número de homicídios de mulheres de cor branca caiu $11,7 \%$, o homicídio de mulheres negras aumentou $12,4 \%$. Nesse contexto, no ano de 2018, 68\% das mulheres mortas no Brasil eram negras. Com relação aos homens, a situação não é diferente, pois em 2018, 75,5\% dos homicídios ocorridos no País eram de homens de cor negra. Logo, as variáveis raça, etnia, gênero e nível socioeconômico são importantes nas análises de criminosos e vítimas, pois há uma desproporção entre essas variáveis (JIBAT; NIGUSSIE, 2015).

A violência contra o negro não é atual, pois perpassa por toda a história brasileira e ocorre por não ser enfrentada pela sociedade, permitindo a configuração de um sistema desumano e injusto (NASCIMENTO; SANTANA, 2021). As diferenças são tão consideráveis que a impressão que se tem é de que negros e não negros vivem 
em países diferentes (CERQUEIRA et al., 2018). Dentro desse contexto, existe um baixo número de políticas públicas voltadas para a redução de riscos e reparação de danos a essa população (NASCIMENTO; SANTANA, 2021). Entretanto, políticas públicas e ações legais para essa população vulnerável são necessárias, mas não suficientes para acabar com o racismo no Brasil (BARBOSA; KOKKONEN; SOUSA, 2021).

Entre os meios mais utilizados para o cometimento de ações violentas em Viçosa, destacase a arma de fogo, que está associada a $61 \%$ dos 2.694 casos de violência identificados. Segundo Waiselfsz (2016), até 1980 a arma de fogo era responsável por $43,9 \%$ dos casos de violência letal, sendo a maioria dos casos cometidos por meio de violência física, facas e sufocamento, entre outros. Entretanto, a partir do período citado, nota-se o seu crescimento chegando a níveis alarmantes em 2003, quando ela passou a representar $70,8 \%$ dos casos de homicídios.
Para Velho (2000) e Cavalcanti (2017), existe uma relação entre a circulação de armas de fogo em determinado local e o tráfico ilícito de drogas, e a essa relação, conforme afirma Vieira et al. (2016), está associada a ocupação irregular das áreas, a baixa presença do Estado e a alta vulnerabilidade social. No caso de Viçosa, conforme ilustra a Figura 5, percebe-se que o tráfico ilícito de drogas e a circulação de armas de fogo estão presentes com mais intensidade exatamente nas regiões de alta vulnerabilidade social, baixa renda per capita e maior segregação socioespacial em relação a outras regiões da cidade.

Esse é o caso das regiões Bom Jesus e Santo Antônio que, das 396 ocorrências registradas de tráfico ilícito de drogas, apresentaram as maiores taxas, ou seja, acima de 9,75\%, bem como de circulação de armas de fogo, taxas superiores a $9,43 \%$. Esses percentuais são considerados altos e se igualam apenas aos registrados nas regiões Passos e Santa Clara.

Figura 5 - Tráfico ilícito de drogas e circulação de armas de fogo nas RUP - 2013/2018.

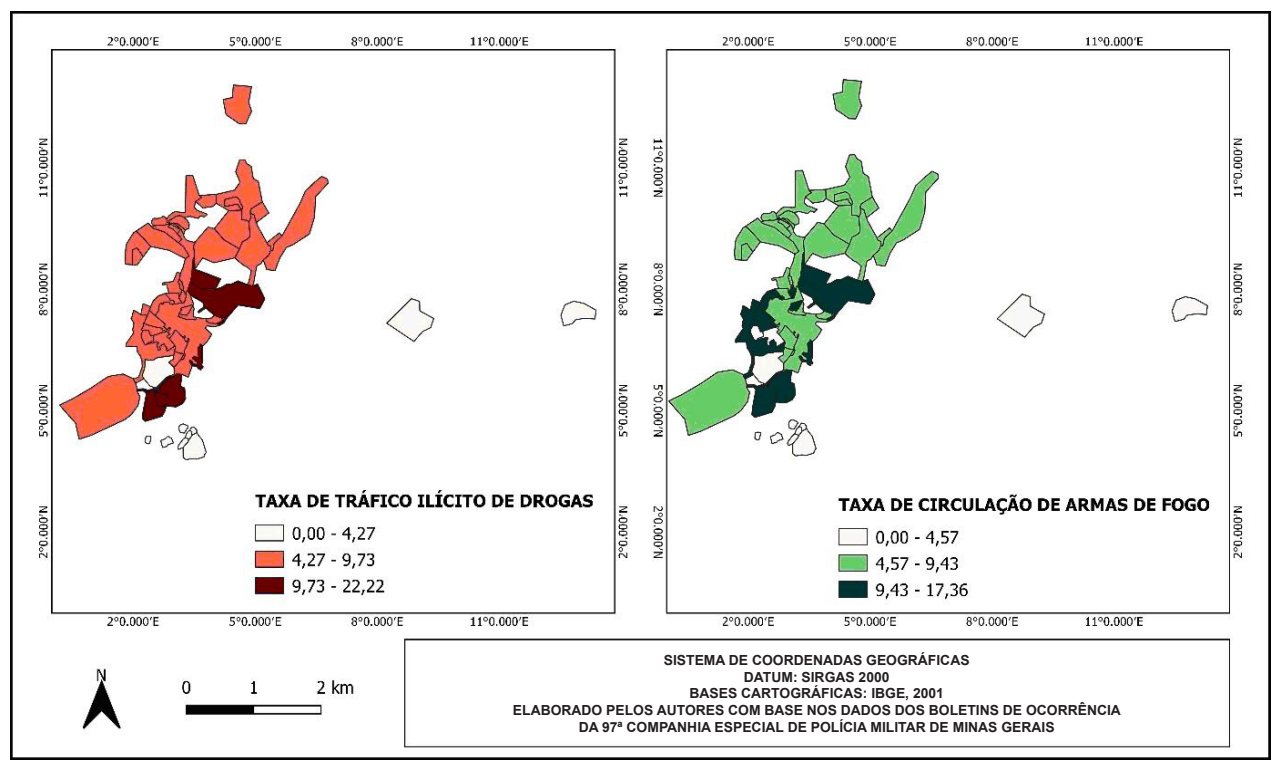

Fonte: os autores, elaborado com base nos boletins de ocorrência da $97^{\mathrm{a}}$ Companhia Especial de Polícia Militar de Minas Gerais (2013/2018) (POLÍCIA MILITAR DO ESTADO DE MINAS GERAIS, 2020).

Em se tratando dos menores registros, notase que taxas abaixo de $4,27 \%$ de tráfico ilícito de drogas foram registradas nas regiões Cachoeirinha,
Acamari, Fátima e Fundão. Nessas regiões também se verificou as menores ocorrências de circulação de armas de fogo, que foram abaixo de $4,57 \%$. 
A análise dos casos de violência por RUP (Figura 6) revela que o fenômeno não assume a mesma configuração em todas as regiões, de forma que os tipos de violência variam conforme a RUP. Percebe-se pelos dados que as maiores taxas de roubos registradas foram na região Centro $(52,38 \%)$ e na região Silvestre $(34,73 \%)$, já as menores registradas foram nas regiões Bom Jesus (2,46\%), Nova Viçosa (4,79\%), Fundão (5,95\%) e Santa Clara (8\%).

Figura 6 - Taxa de roubos, homicídios e agressões físicas por mil habitantes nas RUP - 2013/2018.

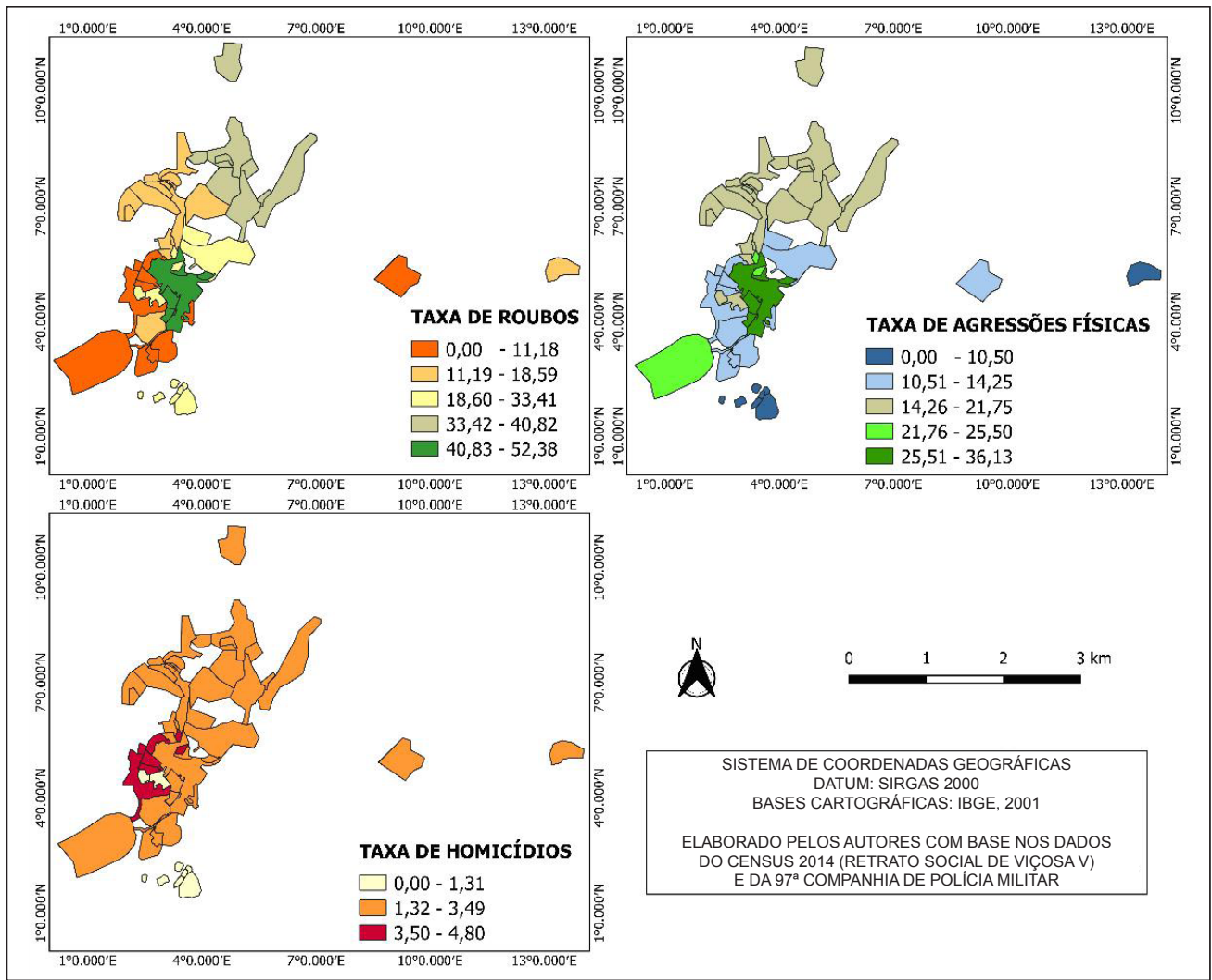

Fonte: os autores, com base nos boletins de ocorrência da $97^{\mathrm{a}}$ Companhia Especial de Polícia Militar de Minas Gerais (2013/2018) (POLÍCIA MILITAR DO ESTADO DE MINAS GERAIS, 2020) e CENSUS (2014).

Em se tratando de agressões físicas, essas foram mais expressivas na região Centro (36,13\%), seguida pelas regiões Nova Viçosa $(21,86 \%)$ e Passos (21,76\%). Com relação aos menores registros, estes foram nas regiões Cachoeirinha $(5,92 \%)$ e Acamari (7,27\%). No caso dos homicídios, as maiores taxas foram registradas nas regiões Passos $(4,8 \%)$ e Santa Clara $(3,56 \%)$, já as menores taxas foram na região Lourdes $(0,57 \%)$ e Acamari, região onde não foi encontrado nenhum registro.

Essa diferenciação no quantitativo e tipos de violência de uma região para outra da cidade é resultado da produção do espaço urbano. Nessa produção, algumas áreas são valorizadas e outras desvalorizadas, e ao serem apropriadas, essas áreas são responsáveis não apenas pelo desenvolvimento de relações sociais, mas também são a base formadora da identidade urbana, estejam essas identidades relacionadas à pobreza, riqueza ou violência (FERREIRA; PENNA, 2005).

No caso da população com pouco ou nenhum poder aquisitivo, o inacesso e a periferização, levam ao seu enclausuramento social e espacial, propiciando a reprodução da pobreza e a dificuldade de mobilidade social (FERREIRA; PENNA, 2005). Nesse contexto, o fato de o Estado intervir 
na conformação do espaço urbano, não leva a resultados esperados ou ao atendimento de objetivos propostos pelo planejamento, uma vez que existe nesse cenário a ação política e econômica de grupos interessados, e da apropriação diferenciada dos seus ônus e benefícios (BITTENCOURT; FARIA, 2021). Logo, para Santos (1993), a cidade como relação social e materialidade a partir de seu modelo socioeconômico e de sua estrutura física torna-se criadora da pobreza, uma vez que faz dos habitantes de áreas periféricas e de cortiços ainda mais pobres.

A partir do exposto, fatores como desigualdade social, infraestrutura precária, baixos salários e desemprego colaboram para a violência urbana (SANTOS; SILVA, 2020), pois são resultado das dinâmicas capitalistas, das lógicas de mercado e do interesse capitalista sobre o espaço urbano (HIDALO et al., 2021), elementos que tornam as áreas mais vulneráveis à ação do crime organizado que, dominando a população, se apropria de suas áreas e as transformam em espaço de sua influência e, a partir delas, comandam a atuação na cidade e o enfrentamento do Estado (FERREIRA; PENNA, 2005).

A relação entre a desigualdade socioeconômica e os tipos de violência a que estão expostas as vítimas nas RUP pode ser melhor verificada na Figura 7, que apresenta o mapa de calor (heatmap) ${ }^{21}$ em que as linhas e colunas foram ordenadas segundo um agrupamento hierárquico. O dendograma mostrado na vertical diz respeito aos agrupamentos obtidos para as RUP, dispostas em linha. Já o dendograma mostrado na horizontal, refere-se aos agrupamentos obtidos para as variáveis, roubos, agressões físicas e homicídios identificados nas RUP e para as variáveis relacionadas às condições socioeconômicas dos habitantes, mais especificamente: taxa de roubos, taxa de agressões físicas, taxa de homicídios, taxa de assistência CREAS, taxa de beneficiados com o Bolsa Família, renda per capita e índice de segregação socioespacial ${ }^{22}$, dispostas em colunas.

Figura 7 - Mapa de calor (heatmap) da violência e desigualdade socioeconômica nas RUP.

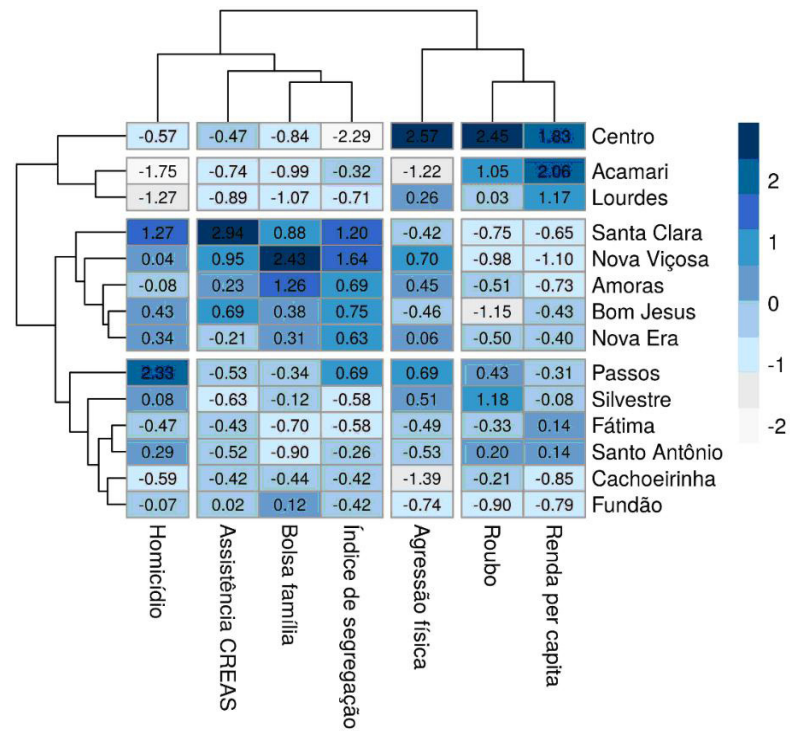

Fonte: os autores, com base nos dados da pesquisa de campo (2018/2019).

${ }^{21}$ Como os dados apresentados para essas variáveis estavam em escalas diferentes, foi necessário padronizá-los, utilizando-se a média e o desvio-padrão dessas variáveis, de modo a permitir que os agrupamentos fossem feitos pela influência das varáveis e não por sua magnitude.

${ }^{22} \mathrm{O}$ índice de segregação elaborado pelos autores não contemplou as regiões Fundão e Cachoeirinha. Para que fosse possível obter o índice de segregação dessas regiões e utilizá-lo nessa análise, calculou-se a média do índice de segregação das duas áreas que estão mais próximas dessas duas regiões. 
Nota-se pelo dendograma horizontal que, inicialmente, foram formados dois agrupamentos maiores. No primeiro agrupamento maior, têm-se as variáveis padronizadas - "renda per capita", "roubo" e "agressões físicas" - indicando que existe certa similaridade entre elas.

Verifica-se ainda que esse agrupamento se ramifica em outros dois agrupamentos, um formado pela variável "agressões físicas" e outro pelas variáveis "roubo" e "renda per capita". A formação desse agrupamento (roubo e renda per capita) e do outro (agressões físicas), isolado dos demais, mas ao mesmo tempo mais próximo, pode ser atribuído ao fato de que os roubos tendem a se concentrar nas regiões de maior renda, enquanto as agressões físicas não apresentam um padrão definido, de forma que tendem a acontecer em áreas de alta e baixa renda (CANO, 1998).

O segundo agrupamento maior é formado pelas variáveis "assistência CREAS", "Bolsa Família", "índice de segregação" e "homicídios". Verifica-se que há uma ramificação desse agrupamento para outros dois, um com a variável homicídios formando um grupo à parte, e as demais variáveis constituindo o outro agrupamento. Autores como Vieira et al. (2016) têm chamado a atenção para a relação dessas variáveis com a desigualdade socioeconômica e a taxa de homicídios. Segundo eles, bairros periféricos, com ocupação irregular, baixa presença do Estado e alta vulnerabilidade social tendem a ter taxas mais elevadas de homicídios, enquanto a mesma situação não se verifica em bairros mais estruturados e com moradias regulares, caso das regiões Centro, Acamari e Lourdes.

Uma análise do dendograma vertical, por RUP, mostra quatro agrupamentos, sendo o primeiro constituído apenas pela região Centro. Os dados evidenciam que o roubo, a agressão física e a renda per capita padronizados são mais elevados nesse agrupamento. Nota-se também que essa é a região com o menor índice de segregação padronizado $(-2,29)$ e baixos valores padronizados de assistência CREAS $(-0,47)$, Bolsa Família $(-0,84)$ e homicídios $(-0,57)$. Essa região, como visto anteriormente, concentra o maior número de pessoas com nível superior e com rendas média e alta, é a mais verticalizada, densamente povoada e dotada de mais infraestrutura e serviços (SILVA, 2016).

Próximo a ela, tem-se o segundo agrupamento formado pelas regiões Acamari e Lourdes, regiões com valores similares aos da região Centro. Observa-se que essas duas regiões são mais similares à região Centro do que às demais regiões. Percebe-se que a região Acamari apresenta os valores mais elevados de renda per capita padronizada $(2,06)$, juntamente com a região Lourdes, com renda per capita padronizada de 1,17.

Nota-se que nessas regiões as taxas de roubo padronizado também são altas ou moderadas, 1,05 e 0,03 , respectivamente, para as regiões Acamari e Lourdes, sendo que a variável agressão física apresentou um valor moderado $(0,26)$ apenas para a região Lourdes. Com relação às outras variáveis, percebe-se que todas elas apresentam valores baixos quando comparadas às outras regiões.

Essa situação diagnosticada corrobora as afirmações de Hermes (2015), que em seu estudo identificou que parte significativa dos roubos, assalto e tráfico de entorpecentes, em Natal, Rio Grande do Norte, tinham ligação direta com oportunidades econômicas, sendo mais frequente em áreas de maior poder aquisitivo. Já os homicídios eram mais frequentes em áreas com menor índice de desenvolvimento, com menor índice de equipamentos sociais e políticas públicas, mais populosas e com altas taxas de irregularidade no que se refere ao uso do solo. Esse contexto se verifica no terceiro e quarto agrupamento, que estão associados a valores mais baixos de renda per capita e taxas mais elevadas de segregação socioespacial, assistência CREAS e Bolsa Família e em que têm-se os valores mais elevados de homicídio.

No caso do terceiro agrupamento, formado pelas regiões Amoras, Nova Viçosa, Bom Jesus e Santa Clara, percebe-se que o poder aquisitivo da população é menor do que o dos habitantes das regiões Centro, Acamari e Lourdes. Além disso, essas regiões apresentam menores infraestrutura, equipamentos públicos e serviços, quando comparadas à região Centro. Nesse agrupamento, a 
taxa de homicídios padronizada apresenta valores de moderados a alto, sendo os valores mais altos registrados nas regiões Bom Jesus $(0,43)$ e Santa Clara (1,27). As variáveis "índice de segregação", "Bolsa Família", "assistência CREAS" e "vulnerabilidade social" criam uma área de destaque no heatmap, mostrando que esses são fatores importantes para a classificação de tais regiões no agrupamento três.

Nota-se que, ao mesmo tempo em que as taxas de homicídio padronizadas apresentam valores de moderado a alto, há um elevado índice de segregação padronizado nessas regiões, com destaque para as regiões Santa Clara $(1,20)$ e Nova Viçosa $(1,84)$, bem como altas taxas de vulnerabilidade social e Bolsa Família padronizadas. Em se tratando de beneficiados com o Bolsa Família, verifica-se nesse agrupamento que os valores mais elevados foram nas regiões Nova Viçosa $(2,43)$, Amoras $(1,26)$ e Santa Clara $(0,88)$.

A assistência do CREAS padronizada mostrou valores altos para as regiões Santa Clara $(2,94)$ e Nova Viçosa $(0,95)$. E, finalmente, os valores obtidos para essas quatro variáveis foram maiores ou iguais aos obtidos para os demais agrupamentos.

Ao se analisar o agrupamento quatro, formado pelas regiões Passos, Fátima, Fundão, Nova Era, Cachoeirinha, Santo Antônio e Silvestre, percebese que esse agrupamento é marcado por valores moderados para todas as variáveis, exceção feita à região Passos, que apresentou um alto valor de homicídio padronizado $(2,33)$, e Silvestre, com alta taxa de roubo padronizada $(1,18)$. As discrepâncias verificadas nessas duas regiões são resultado da heterogeneidade populacional existente, uma vez que a região Silvestre, como afirma Ribeiro Filho (1997), concentra uma população de renda mais alta em alguns bairros e de renda mais baixa em outros, e o mesmo caso ocorre com a região Passos, onde há bolsões de pobreza, como na favela Rebenta Rabicho.

De forma geral, ao se comparar os quatro agrupamentos, nota-se claramente uma diferenciação entre eles quanto às variáveis, ou seja, as regiões de planejamentos foram agrupadas de forma a constituir grupos compostos por regiões que apresentam alguma similaridade quanto às variáveis em estudo.

Assim, no primeiro e no segundo agrupamento, formados, respectivamente, pelas regiões Centro, e Acamari e Lourdes, existem valores de moderado a alto para a variável padronizada "roubo", valores altos para a variável "renda per capita" e valores baixos ou moderados para as variáveis relacionadas a benefícios sociais, índice de segregação e homicídios. No terceiro agrupamento, têm-se valores elevados para as variáveis relacionadas a benefícios sociais, e taxas de homicídios superiores às observadas nos agrupamentos um e dois. Por fim, o agrupamento quatro é marcado por valores moderados para quase todas as variáveis, exceções pontuais, como dito anteriormente, foram percebidas para as regiões Passos e Silvestre.

Esses resultados vão ao encontro das conclusões de Cano (1998), em uma pesquisa no Rio de Janeiro, em que o autor percebeu que o espaço de residência e as características da pessoa são fatores determinantes nos tipos de vitimização. Dessa forma, a morte violenta é maior entre os moradores de áreas pobres e com escassos serviços urbanos do que entre as pessoas de classe social mais elevada e que residem em espaços com melhor infraestrutura urbana e serviços. Estas, por sua vez, tendem a ser mais protegidas desse tipo de violência.

Conforme afirma o autor supracitado, essa mesma tendência se dá em relação ao roubo, pois são as pessoas com renda mais elevada e residentes nas áreas de maior desenvolvimento urbano que correm maior risco de sofrerem esse tipo de violência. Já as agressões físicas, ocorrem em áreas de renda mais elevada, mas também de renda mais baixa, de forma que pode-se entender que ela não apresenta um padrão definido como o roubo e o homicídio.

\section{Considerações finais}

O presente estudo possibilitou caracterizar e compreender a incidência desigual dos roubos, homicídios e agressões físicas na cidade de Viçosa 
nos últimos seis anos. Além disso, permitiu relacionar esses dados com o perfil das vítimas, com as condições socioeconômicas, a infraestrutura e os serviços presentes nestas regiões.

Os dados evidenciaram que, tal qual ocorre em outras cidades, a violência e os tipos de violência em Viçosa variam conforme a idade, cor e sexo da vítima, bem como com seu local de residência e situação socioeconômica. Assim, as maiores vítimas de roubos, homicídios e agressões físicas em Viçosa são os jovens do sexo masculino, principalmente na faixa etária de 20 a 24 anos.

No caso dos roubos, as maiores vítimas são pessoas de cor branca, residentes nas áreas de renda mais elevada. Já no caso de homicídios e agressões físicas, as principais vítimas são as pessoas de cor negra/parda, com renda mais baixa, moradoras de regiões com poucos ou nenhum serviço e infraestrutura, geralmente em áreas mais segregadas.

O mapa de calor (heatmap) evidenciou discrepâncias em relação às RUP relacionadas aos tipos de violência e as desigualdades socioeconômicas. A formação dos agrupamentos, a partir das variáveis socioeconômicas e dos tipos de violência, revelou que, de forma geral, no caso de Viçosa, as maiores taxas de roubos tendem a se concentrar nas regiões de maior renda e com baixos índices de segregação, atendimento CREAS e Bolsa Família, caso das regiões Centro, Lourdes e Acamari. Ao mesmo tempo, notou-se que o alto índice de homicídios ocorreu nas regiões em que havia baixos valores de renda per capita e valores elevados de segregação socioespacial, Bolsa Família e assistência CREAS. Esses resultados evidenciam que as diferenças nessas variáveis estão associadas a índices mais baixos ou elevados de determinados tipos de violência.

Logo, conclui-se que a desigualdade socioeconômica a qual estão expostos os jovens das diferentes RUP de Viçosa é o elemento propiciador da vitimização deles. Isso porque os tipos de violência vivenciados na cidade não atingem a todos da mesma forma, sendo que a violência é um fenômeno que varia conforme a RUP, idade, sexo, cor e condições socioeconômicas.

\section{Referências}

ABRAMOVAY, M.; CASTRO, M. G; PINHEIRO, L. C.; LIMA, F. S.; MARTINELli, C. C. Juventude, violencia e vulnerabilidade social na América Latina: desafios para políticas públicas. Brasília: Unesco; 2002.

ANDRESEN, M. A. A spatial analysis of crime in Vancouver, British Columbia: a synthesis of social disorganization and routine activity theory. The Canadian Geographer, New York, v. 50, n. 4, p. 487-502, 2006. Disponível em: https://bit. ly/3g4Vz5m. Acesso em: 10 set. 2020.

BARBOSA, X. C.; KOKKONEN, R. L. F.; SOUSA, S. B. "Eu não consigo respirar": racismo estrutural e os desafios da educação para as relações étnico-raciais na rede federal de educação profissional, científica e tecnológica-brasil. Educação Profissional e Tecnológica em Revista, João Pessoa, v. 5, p. 29-51, 2021. Número Especial. Disponível em: https://bit.ly/353kAYj. Acesso em: 05 mar. 2021.

BARDIN, L. Análise de conteúdo. Lisboa: Edições 70, 2011.

BASTOS FILHO, R. A.; ALMEIDA PINTO, M. N.; FIÚZA, A. L. C.; REZENDE, D. F. A. The elaboration of a socio-spatial segregation index as a tool for the management and analysis of the urban space of Viçosa, MG. Interações (Campo Grande), v. 20, n. 3, p. 707-723, 2019. Disponível em: https://bit.ly/2RBtnxq. Acesso em: 10 set. 2020 .

BATELLA, V. Centro, Centralidade e cidade média: apontamentos sobre Viçosa-MG. In: SOUSA, D. T.; BATELLA, W. B. Cidades, territórios e direitos. Viçosa: Editora UFV, 2017. p. 155-173.

BEATO FILHO, C. C. Crime e cidades. @Metrópolis: Revista Eletrônica de Estudos Urbanos e Regionais, Rio de Janeiro, ano 3, n. 9, p. 59-61, 2012.

BEATO, C.; PEIXOTO, B. T.; ANDRADE, M. V. Crime, oportunidade e vitimização. Revista Brasileira de Ciências Sociais, São Paulo, v. 19, n. 55, p. 73-89, 2004. Disponível em: https://bit. ly/3ivgPCI. Acesso em: 12 set. 2020. Doi: https:// doi.org/10.1590/S0102-69092004000200005 
BITTENCOURT, T. A.; FARIA, J. R. V. Distribuição de investimentos públicos, infraestrutura urbana e desigualdade socioespacial em Curitiba. urbe: Revista Brasileira de Gestão Urbana, Curitiba, n. 13, p. 1-20, 2021. Disponível em: https://bit. ly/3g7fqR1. Acesso em: 10 mar. 2021. Doi: https:// doi.org/10.1590/2175-3369.013.e20190300

BORGES, D. Vitimização e sentimento de insegurança no Brasil em 2010: teoria, análise e contexto. Mediações: Revista de Ciências Sociais, Londrina, v. 18, n. 1, p. 141-163, 2013. Disponível em: https:// bit.ly/3g79W9j. Acesso em: 14 set. 2020. Doi: http:// dx.doi.org/10.5433/2176-6665.2013v18n1p141

BRANDÃO, T. S.; COSTA, J. H. Um olhar sobre a violência homicida em Mossoró/RN/Brasil e sua relação com o turismo de eventos. Revista Turydes: Turismo y Desarrollo, Málaga, v. 8, n. 18, 2015. Disponível em: https://bit.ly/3cvUNMn. Acesso em: 11 set. 2020 .

BRASIL. Lei $\mathrm{n}^{\circ} 12.852$, de 5 de agosto de 2013. Institui o Estatuto da Juventude e dispõe sobre os direitos dos jovens. Diário Oficial da União, Brasília, 6 ago. 2013. Seção 1, p. 1. Disponível em: https://bit.ly/3ivEpiH. Acesso em: 10 set. 2020.

BRASIL, Ministério da Saúde. DATASUS: Informações de Saúde (TABNET). Brasília, 2020a. Disponível em: https://bit.ly/3cz3Ts2. Acesso em: 15 mar. 2020.

BRASIL. Ministério do Desenvolvimento Social e Combate à Fome. Bolsa Família. Brasília, 2020b. Disponível em: https://bit.ly/3gk5Uck. Acesso em: 10 set. 2020 .

CALDEIRA, T. P. R. Cidade de muros: crime, segregação e cidadania em São Paulo. 2. ed. São Paulo: EDUSP, 2008.

CÁMARA DE COMERCIO DE BOGOTÁ. Protocolo de Bogotá: sobre calidad de datos de homicidio en América Latina y el Caribe. Bogotá, 2015. Disponível em: https://bit.ly/3x9TD17. Acesso em: 16 set. 2020.

CANO, I. Análise espacial da violência no município do Rio de Janeiro. In: NAJAR, A. L.; MARQUES, E. C. (Org.). Saúde e espaço: estudos metodológicos e técnicas de análise. Rio de Janeiro: Fiocruz, 1998. Cap. 12, p. 239-273. Disponível em: https://bit.ly/3gpR4B1. Acesso em: 10 set. 2020.
CARRIÓN, F. Violencia urbana: un asunto de ciudad. EURE (Santiago), v. 34, n. 103, p. 111130, 2008. Disponível em: https://bit.ly/3xaCCUE. Acesso em: 10 set. 2020. Doi: http://dx.doi.org/10. 4067/S0250-71612008000300006

CAVALCANTI, R. C. As dinâmicas da violência urbana na América Latina. Século XXI: Revista de Ciências Sociais, Santa Maria, v. 7, n. 2, p. 226251, 2017. Disponível em: https://bit.ly/3zpvWE2. Acesso em: 15 set. 2020. Doi: https://doi.org/10. $5902 / 2236672531915$

CECCATO, V. Public space and the situational conditions of crime and fear. International Criminal Justice Review, London, v. 26, n. 2, p. 6979, 2016. Disponível em: https://bit.ly/354FS84. Acesso em: 10 set. 2020. Doi: https://doi.org/10. $1177 / 1057567716639099$

CERQUEIRA, D. R. D. C., LOBÃO, W. J. A.; CARVALHO, A. X. Y. D. O jogo dos sete mitos e a miséria da segurança pública no Brasil. IPEA, Rio de Janeiro, n. 1144, p. 1-30, 2005. Disponível em: http://repositorio.ipea.gov.br/bitstream/ 11058/1778/1/TD_1144.pdf. Acesso em: 10 set. 2020.

CERQUEIRA, D. (Coord.). Atlas da violência 2018. Brasília: Ipea; FBSP, 2018. Disponível em: https://bit.ly/3cuMoJ0. Acesso em: 10 mar. 2021.

CERQUEIRA, D. (Coord.). Atlas da violência 2019. Brasília: Ipea; FBSP, 2019. Disponível em: https://bit.ly/3zbDtpM. Acesso em: 11 set. 2020.

CERQUEIRA, D. (Coord.). Atlas da violência 2020. Brasília: Ipea; FBSP, 2020. Disponível em: https://bit.ly/3g3oJ4J. Acesso em: 10 mar. 2021.

COHEN, L. E.; FELSON, M. Social change and crime rate trends: a routine activity approach. American Sociological Review, Menasha, v. 44, n. 4, p. 588-608, 1979. Disponível em: https://bit. ly/354pXXc. Acesso em: 10 set. 2020. Doi: http:// dx.doi.org/10.2307/2094589

COULON, A. A Escola de Chicago: introdução e origens. São Paulo: Editora Papirus, 1995.

CENSUS - Centro de Promoção do Desenvolvimento Sustentável. Retrato social de Viçosa. Viçosa, MG: Census, 2014. 
FARRELLY, C. M.; SCHWARTZ, S. J.; AMODEO, A. L.; FEASTER, D. J.; STEINLEY, D. L.; MECA, A.; PICARIELLO, S. The analysis of bridging constructs with hierarchical clustering methods: an application to identity. Journal of Research in Personality, San Diego, v. 70, p. 93-106, 2017. Disponível em: https://bit.ly/2TTV2dT. Acesso em: 10 set. 2020. Doi: https://doi.org/10.1016/j. jrp.2017.06.005

FERREIRA, I. F. C. B.; PENNA, N. A. Território da violência: um olhar geográfico sobre a violência urbana. GEOUSP Espaço e Tempo (Online), v. 9, n. 1, p. 155-168, 2005. Disponível em: https://www. revistas.usp.br/geousp/article/view/73979/77638. Acesso em: 10 set. 2020. Doi: https://doi. org/10.11606/issn.2179-0892.geousp.2005.7397

FUNDAÇÃO JOÃO PINHEIRO. Índice mineiro de responsabilidade social. Belo Horizonte: Fundação João Pinheiro, 2019.

GADEA, C. A.; SILON, J.; ROSA, F.; CEZAR, M. S.; DICK, H. Trajetórias de jovens em situação de vulnerabilidade social: sobre a realidade juvenil, violência intersubjetiva e políticas para jovens em Porto Alegre RS. Sociologias, Porto Alegre, v. 19, n. 45, 2018. Disponível em: https://bit. ly/3x9yxA2. Acesso em: 10 set. 2020. Doi: https:// doi.org/10.1590/15174522-019004512

GODOY, A. S. Pesquisa qualitativa: tipos fundamentais. Revista de Administração de Empresas, São Paulo, v. 35, n. 3, p. 2-29, 1995. Disponível em: https://bit.ly/2TPDvU1. Acesso em: 10 set. 2020. Doi: https://doi.org/10.1590/S0034-75901995000 300004

GOMES, P. C. C. A condição urbana: ensaios de geopolítica da cidade. Bertrand Brasil, 2002.

HERMES, I.; ALVES, C.; BRANDÃO, T. Rastros de pólvora: metadados 2015. Natal: Edição dos Autores, 2015.

HIDALGO, D.; SILVEIRA, F.; PADILHA, D.; BASSANI, A. F.; NASCIMENTO, I. Violencia urbana y políticas de seguridad: análisis en cuatro ciudades latinoamericanas. EURE: Revista de Estudios Urbano Regionales, Santiago de Chile, v. 47, n. 141, p. 165-182, 2021. Disponível em: https://bit.ly/3pDBoPd. Acesso em: 10 jun. 2021.
IBGE. Censo Brasileiro de 2010. Rio de Janeiro: IBGE, 2020.

IBGE. Cidades - Viçosa, 2020. Rio de Janeiro: IBGE, 2020.

IBGE. Bases cartográficas 2001. Rio de Janeiro: IBGE, 2020.

JANOWITZ, M. Sociological theory and social control. American Journal of Sociology, Chicago, v. 81, n. 1, p. 82-108, Jul. 1975. Disponível em: https://bit.ly/2Tj3dAg. Acesso em: 10 set. 2020.

JIBAT, N.; NIGUSSIE, B. Criminality and Victimization in Oromia, Ethiopia: Analysis of 2011/ 2012 Police Data. SAGE Open, New York, v. 5, n. 1, 2015. Disponível em: https://bit.ly/3waLXf1. Acesso em: 12 mar. 2020. Doi: https://doi.org/10. $1177 \% 2 \mathrm{~F} 2158244014565335$

KOLDE, R. Pheatmap: Pretty heatmaps [Software]. $\mathrm{R}$ package version 1.0. 8. 2015. Disponível em: https://bit.ly/3pKpgfi. Acesso em: 10 set. 2020.

KUBRIN, C. E; WEITZER, R. New directions in social disorganization theory. Journal of Research in Crime and Delinquency, New York, v. 40, n. 4, p. 374-402, 2003. Disponível em: https://bit. ly/3pKpgfi. Acesso em: 10 set. 2020. Doi: https:// doi.org/10.1177/0022427803256238

LEMGRUBER, J.; MUSUMECI, L.; RAMOS, S. Por que é tão difícil implementar uma política de segurança. Observatório da Cidadania, São Paulo, v. 6, p. 46-54, 2002.

LOUDERBACK, E. R.; SEN ROY, S. Integrating social disorganization and routine activity theories and testing the effectiveness of Neighbourhood crime watch programs: Case study of MiamiDade County, 2007-15. The British Journal of Criminology, London, v. 58, n. 4, p. 968-992, 2018. Disponível em: https://bit.ly/3g4nFxE. Acesso em: 10 set. 2020. Doi: https://doi.org/10.1093/bjc/ azx062

MAGRINI, M. A. O. Interações entre violência e cidades: em busca de uma definição de violência urbana. Caderno Prudentino de Geografia, Presidente Prudente, v. 1, n. 36, p. 83-98, 2014. Disponível em: https://bit.ly/3g9Lrbi. Acesso em: 10 set. 2020 . 
MARIA, A. C. S. A produção do espaço urbano da zona sul de Viçosa-MG: empreendimentos horizontais na bacia do ribeirão São Bartolomeu. 2016. Tese (Doutorado em Arquitetura e Urbanismo) Universidade Federal de Viçosa, Viçosa, 2016.

MISSE, M. Malandros, marginais e vagabundos: a acumulação social da violência no Rio de Janeiro. 1999. Tese (Doutorado em Sociologia) - Instituto Universitário de Pesquisas do Rio de Janeiro, Rio de Janeiro, 1999.

MORIARTY, L. J.; WILLIAMS, J. E. Examining the relationship between routine activities theory and social disorganization: an analysis of property crime victimization. American Journal of Criminal Justice, New York, v. 21, p. 43-59, 1996. Disponível em: https://bit.1y/2SnXB7p. Acesso em: 16 set. 2020 .

NASCIMENTO, E.; SANTANA, L. Quando nenhum lugar é seguro: a violência contra corpos negros em Alagoas. Revista Argumentos, Montes Claros, v. 18, n. 1, p. 75-93, jan./jun. 2021. Disponível em: https://bit.ly/3xexL4P. Acesso em: 16 mar. 2021. Doi: https://doi.org/10.32887/issn.25272551v18n1p.75-93

POLÍCIA MILITAR DO ESTADO DE MINAS GERAIS. 97 ${ }^{\mathrm{a}}$ Companhia Especial de Polícia Militar de Minas Gerais. Boletins de ocorrência: 2013/2018. Belo Horionte, 2020.

PORTES, A. Social capital: Its origins and applications in modern sociology. Annual Review of Sociology, Palo Alto, v. 24, n. 1, p. 1-24, 1998. Disponível em: https://bit.ly/2TfIvks. Acesso em: 16 set. 2020 .

PUTNAM, R. 2000: Bowling alone: the collapse and revival of American community. New York: Simon and Schuster. 2000.

RIBEIRO FILHO, G. B. A formação do espaço construído: cidade e legislação urbanística em Viçosa, MG. 1997. Dissertação (Mestrado em Urbanismo) - Universidade Federal do Rio de Janeiro, Rio de Janeiro, 1997.

SAMPSON, R. J.; GROVES, W. B. Community structure and crime: Testing social-disorganization theory. American journal of sociology, Chicago, v. 94, n. 4, p. 774-802, 1989. Disponível em: https://bit.ly/3waVAdp. Acesso em: 12 set. 2020.
SAMPSON, R. J.; MORENOFF, J. D.; GANNONROWLEY, T. Assessing "neighborhood effects": Social processes and new directions in research. Annual Review of Sociology, Palo Alto, v. 28, n. 1, p. 443-478, 2002. Disponível em: https://bit. ly/3gdmKLv. Acesso em: 16 set. 2020.

SAMPSON, R. J.; WOOLDREDGE, J. D. Linking the micro- and macro-level dimensions of lifestyleroutine activity and opportunity models of predatory victimization. Journal of Quantitative Criminology, Dordrecht, v. 3, n. 4, p. 371-393, 1987. Disponível em: https://bit.ly/3gq706q. Acesso em: 16 set. 2020.

SANTOS, A. M.; SILVA, A. Violência urbana e suas representações sociais. Brazilian Journal of Development, Curitiba, v. 6, n. 7, p. 47370-47384, 2020. Disponível em: https://bit.ly/3x1D8UO. Acesso em: 16 mar. 2021.

SANTOS, J. V. T. Violências e dilemas do controle social nas sociedades da "modernidade tardia". São Paulo em perspectiva, São Paulo, v. 18, n. 1, p. 3-12, 2004. Disponível em: https://bit. ly/3g6DQuk. Acesso em: 15 set. 2020. Doi: https:// doi.org/10.1590/S0102-88392004000100002

SANTOS, M. A urbanização brasileira. São Paulo: Edusp, 1993.

SCHVASBERG, B. Tendências e problemas da urbanização contemporânea no Brasil. In: CASTRIOTA, L. B. (Org.). Urbanização brasileira: redescobertas. Belo Horizonte: C/ Arte, 2003. p. 43-63.

SHAW, C. R.; McKAY, H. D. Juvenile delinquency and urban areas: a study of delinquency in relation to differential characteristics of local communities in American cities. Chicago: University of Chicago Press, 1969.

SILVA, M. L. Expansão da cidade de Viçosa (MG): a dinâmica centro-periférica. 2016. Dissertação (Mestrado em Geografia) - Universidade Federal do Espírito Santo, Vitória, 2016.

SILVA, M. P.; SANTANA, L. L. S.; ALVES, L. S.; CHAGAS, C. A. N. Análise socioespacial da violência na $12^{\mathrm{a}}$ AISP: o uso do território, geoinformação e influências da violência urbana em Belém-PA. Revista GeoAmazônia, Belém, v. 2, n. 4, p. 190-205, 2014. Disponível em: https://bit. ly/3wa8oAW. Acesso em: 16 set. 2020. 
SIMCHA-FAGAN, O. M.; SCHWARTZ, J. E. Neighborhood and delinquency: an assessment of contextual effects. Criminology, Columbus, v. 24, n. 4, p. 667-699, 1986. Disponível em: https://bit. ly/3v9u6Uv. Acesso em: 17 set. 2020.

SINHORETTO, J. Mapa do encarceramento: os jovens do Brasil. Brasília: Secretaria Nacional da Juventude, 2015. Disponível em: https://bit. ly/2SnjW59. Acesso em: 10 set. 2020.

SMITH, W. R.; FRAZEE, S. G.; DAVISON, E. L. Furthering the integration of routine activity and social disorganization theories: small units of analysis and the study of street robbery as a diffusion process. Criminology, Columbus, v. 38, n. 2, p. 489-524, 2000. Disponível em: https://bit. ly/2RDSRKz. Acesso em: 16 set. 2020.

STARK, R. Deviant places: a theory of the ecology of crime. Criminology, Columbus, v. 25, n. 4, p. 893-910, 1987. Disponível em: https://bit. ly/2SmfxiV. Acesso em: 12 set. 2020. Doi: https:// doi.org/10.1111/j.1745-9125.1987.tb00824.x

THOMAS, W.; ZNANIECKI, Florian. The concept of social disorganization. In: TRAUB, S. H.; LITTLE, C. B. Theories of deviance. Itasca: F. E. Peacock, 1999. p. 67-70.

VELHO, G. Individualismo, anonimato e violência na metrópole. Horizontes Antropológicos, Porto Alegre, v. 6, n. 13, p. 15-29, 2000. Disponível em: https://bit.ly/3pDnc8y. Acesso em: 12 set. 2020.

VIEIRA, D. C. M.; BORGES, R. H. M.; SANTOS, C. S.; CHAGAS, C. A. N. Território Criminalidade e Violência: Uma Análise dos Homicídios na $4^{\mathrm{a}}$ e $5^{\text {a }}$ AISP, Belém-Pará. Boletim Amazônico de Geografia, Belém, v. 3, n. 5, p. 152-174, jan. 2016. Disponível em: https://bit.ly/3gaB7jD. Acesso em: 12 set. 2020. Doi:10.17552/2358-7040/bag.v3n5 p152-174

VIÇOSA. Prefeitura Municipal. Programa bolsa família. Viçosa: Secretaria de Assist. Social, 2020.

VILLAÇA, F. Reflexões sobre as cidades brasileiras. Studio Nobel, 2012.

WAISELFSZ, J. J. Mapa da violência 2016: homicídios por armas de fogo no Brasil. Rio de Janeiro: FLACSO Brasil, 2016. Disponível em: https://bit.ly/3zj1k6T. Acesso em: 12 set. 2020.
ZALUAR, A; RIBEIRO, A. P. A. Teoria da eficácia coletiva e violência: o paradoxo do subúrbio carioca. Novos Estudos CEBRAP, São Paulo, n. 84, p. 175-196, 2009. Disponível em: https://bit. ly/2SmCL8A. Acesso em: 12 set. 2020. 
